\title{
Mapping arctic landfast ice extent using L-band synthetic aperture radar interferometry
}

\author{
Franz J. Meyer ${ }^{\text {a,* }}$, Andrew R. Mahoney ${ }^{\text {a }}$, Hajo Eicken ${ }^{a}$, Casey L. Denny ${ }^{\text {b }}$, \\ Hyunjin C. Druckenmiller ${ }^{a}$, Stefan Hendricks ${ }^{c}$ \\ a Geophysical Institute, University of Alaska Fairbanks, Fairbanks, Alaska, 99775, USA \\ ${ }^{\mathrm{b}}$ Alaska Satellite Facility, University of Alaska Fairbanks, Fairbanks, Alaska, 99775, USA \\ c Alfred Wegener Institute for Polar and Marine Research, Bremerhaven, D-27570, Germany
}

\section{A R T I C L E I N F O}

\section{Article history:}

Received 19 January 2011

Received in revised form 9 June 2011

Accepted 11 June 2011

Available online 22 July 2011

\section{Keywords:}

Remote sensing

Climate change

Arctic

Synthetic aperture radar interferometry

SAR coherence

Landfast ice

Sea ice

ALOS

PALSAR

\begin{abstract}
A B S T R A C T
In recent years methods have been developed to extract the seaward landfast ice edge from series of remote sensing images, with most of them relying on incoherent change detection in optical, infrared, or radar amplitude imagery. While such approaches provide valuable results, some still lack the required level of robustness and all lack the ability to fully automate the detection and mapping of landfast ice over large areas and long time spans. This paper introduces an alternative approach to mapping landfast ice extent that is based on coherent processing of interferometric L-band Synthetic Aperture Radar (SAR) data. The approach is based on a combined interpretation of interferometric phase pattern and interferometric coherence images to extract the extent and stability of landfast ice. Due to the low complexity of the base imagery used for landfast ice extraction, significant improvements in automation and reduction of required manual interactions by operators can be achieved. A performance analysis shows that L-band interferometric SAR (InSAR) data enable the mapping of landfast ice with high robustness and accuracy for a wide range of environmental conditions.
\end{abstract}

(c) 2011 Elsevier Inc. All rights reserved.

\section{Introduction}

Landfast sea ice is a key element of the Arctic coastal system. Its presence can mitigate the effect of winter storms on the coast and impact the degree of coastal erosion (Lantuit \& Pollard, 2008). Landfast ice is also of great importance to coastal communities who use the ice for travel and to hunt. Furthermore, its presence and stability is of considerable economic importance for offshore oil and gas development in parts of the Arctic (Eicken et al., 2009). In recent years, there has been a reduced presence of landfast sea ice throughout the Arctic. Divine and Dick (2006) and Divine et al. (2004) note a negative trend in mean landfast sea ice extent in the Kara Sea since 1953. In the Canadian Archipelago, formerly semipermanent plugs of multiyear landfast ice have fractured or disintegrated several times since 1997 (Alt et al., 2006). Along Alaska's northern coast, although the annual maximum extent has changed little, landfast sea ice appears to be forming later and breaking up earlier than it did during the 1970s, possibly in response to regional

\footnotetext{
* Corresponding author. Tel.: +1 907474 7767; fax: +1 9074747290. E-mail addresses: fmeyer@gi.alaska.edu (F.J. Meyer), mahoney@gi.alaska.edu (A.R. Mahoney), hajo.eicken@gi.alaska.edu (H. Eicken), cldenny@alaska.edu (C.L. Denny), Stefan.Hendricks@awi.de (S. Hendricks).
}

warming and the overall retreat of sea ice in the Arctic (Mahoney et al., 2007). As a result of these changes together with increasing commercial interest in coastal areas of the Arctic, it has become important in recent years to be able to robustly and routinely identify and map landfast ice from remote sensing data.

With this paper, we present an approach to landfast sea ice detection based on interferometric processing of image pairs acquired by spaceborne L-band Synthetic Aperture Radar (SAR) sensors such as PALSAR on board the Japanese Advanced Land Observing Satellite (ALOS). With interferometric phase and coherence, SAR interferometry (InSAR) comprises two measurements that have the potential for assessing both landfast ice extent and its stability. Here, stability is defined as the absence of motion or deformation that would compromise the integrity of the landfast ice, such as ridge building or ice break-out events. Interferometric coherence is an indicator of the degree to which surfaces remain unchanged, in particular with respect to scattering properties, potential movement, or deformation. Interferometric phase reveals information about $\mathrm{cm}$ - to $\mathrm{dm}$-scale surface motion, and therefore provides very detailed information about surface stability.

The intent of this paper is to present a technique for landfast ice mapping from L-band InSAR and demonstrate its suitability for automated landfast sea ice detection. We compare the results of this 
technique with those of an independent reference technique and conduct a rigorous performance evaluation of L-band InSAR for monitoring landfast ice. For this comparison, we selected two different regions of the Alaska coast. These regions were chosen in part due to the availability of data through the Alaska Satellite Facility at the University of Alaska Fairbanks, but also due to the socioeconomic significance and availability of background information on landfast ice in Alaska. Using examples, we demonstrate the high performance of L-band InSAR for several stages throughout the sea-ice season and for different geographic and climatic settings. The evaluation shows significant potential in reducing data and processing efforts, increasing reliability of landfast ice detection, as well as reducing processing complexity and required manual interaction. Moreover, we find that L-band InSAR has the potential to reveal additional information about small-scale ice dynamics and motion.

The paper also provides an assessment of the spatio-temporal data coverage achieved by current L-band InSAR systems. Although the amount of available data is currently limited, it is pointed out that the fleet of planed and upcoming L-band SAR systems will improve data coverage and availability in the near future.

\section{Definition of landfast ice and selection of reference technique}

Landfast ice is defined by the World Meteorological Organization as "sea ice which remains fast along the coast, where it is attached to the shore, to an ice wall, to an ice front, or over shoals, or between grounded icebergs" (World Meteorological Organization, 1970). Operational ice charts such as those produced by the US National Ice Center (NIC), the Canadian Ice Service (CIS) and the Russian Arctic and Antarctic Research Institute (AARI) have routinely identified landfast sea ice from a variety of remote sensing data for several decades. These charts are compiled by skilled observers who often have to rely on a clearly defined edge such as a lead of open water or a zone of deformed ice to delineate the extent of landfast sea ice (J. Pena, personal fs, 2005). However, there is often no clear edge or morphological difference between the landfast ice and drifting pack ice. In such cases, the only way to identify the seaward landfast ice edge is to delineate the boundary between sea ice that exhibits motion and sea ice that remains stationary. Hence, a single image is insufficient to distinguish the seaward landfast ice edge in all cases.

Mahoney et al. $(2004,2006)$ laid out an alternative definition relying on consecutive images to identify sea ice that was contiguous with the coastline and remained stationary over a 20-day time period. Using this approach with Radarsat-1 SAR imagery, they studied landfast sea ice along the northern Alaska coast between 1996 and 2004 (Mahoney et al., 2007) and frequently found that the boundary between moving and stationary ice was not marked by any feature readily distinguished in individual scenes, highlighting the need to consider a time interval when defining landfast sea ice.

Others have also applied time-dependent definitions of landfast ice in remote sensing-based studies. Giles et al. (2008) applied a correlation-based motion detection method to identify stationary regions in co-located pairs of Radarsat-1 SAR imagery over East Antarctica. After downsampling by a factor of 4 to remove speckle, this technique was successful in identifying sea ice that remained stationary over time periods of up to 20 days provided the data contained sufficient texture. Fraser et al. (2010) derived a dataset of 20-day mean-value composite images using Moderate Resolution Imaging Spectrometer (MODIS) data. Owing to the contrasting spectral signatures of open water and ice, regions of stationary ice or persistent leads will tend to generate values at opposite ends of the range of pixel values within a composite image. Conversely, drifting ice tends to generate values close to the middle. Provided the seaward edge of landfast ice is marked by a recurring lead, Fraser et al.'s technique is capable of generating landfast ice maps over vast areas such as the East Antarctic coastline.
Table 1 summarizes recent approaches used to detect landfast sea ice. The length of the time interval used by these approaches determines how long sea ice must remain stationary in order to be considered landfast and therefore affects the extent of landfast ice detected. Longer time intervals will tend to identify smaller areas of landfast ice since it is less likely that ice will remain stationary for the whole period. Conversely, shorter time intervals may misidentify drifting sea ice that might come to rest temporarily against the landfast ice, but lacks any physical attachment. There is no fixed time interval to define landfast sea ice, but the frequent usage of 20 days reflects an effort to strike a balance that allows the study of the annual landfast ice cycle while reducing the risk of misidentification. Besides these considerations, the time interval used is often also affected by data availability constraints.

With this paper, we present an alternative approach to mapping landfast ice extent and assessing ice stability based on 46-day L-band SAR interferograms. The intent of the paper is to introduce the basics of the technique and showcase its performance and reliability by comparison to a well-established reference technique. For these purposes we have selected the technique described by Mahoney et al. (2004, 2006), which also uses active microwave remote sensing data and offers the closest match in terms of spatial resolution. An added advantage of this technique over the others listed in Table 1 is that it was developed in-house at the University of Alaska Fairbanks and hence its performance characteristics are well known to the authors. Thus, we are able to assign quantifiable confidence measures to the reference technique results and differences between test and reference method are easier to interpret.

\section{Landfast ice detection methods}

\subsection{Landfast ice mapping based on L-band SAR Interferometry}

SAR represents an obvious alternative to optical satellites for mapping landfast ice on a routine and consistent basis. As an active sensor, it is independent of weather and solar illumination, which makes it an essential tool for any routine mapping effort that has to perform consistently during Arctic winters. Despite speckle (Lee, 1981; Lee et al., 1994), geometric distortions, and issues of image interpretation, there is a well-established record of SAR for studying the arctic environment, such as its use for the assessment of glacier motion (Erten et al., 2009; Meyer, 2007; Rignot, 2001), snow line mapping (Adam et al., 1997), and facies discrimination (Partington, 1998).

Despite its significant potential, use of InSAR for landfast ice mapping was limited in the past (Dammert et al., 1998; Morris et al., 1999) as most spaceborne sensors operated at C-band. At this frequency range, scattering properties of landfast ice surfaces change rapidly resulting in a rapid degradation of the interferometric coherence over time. While earlier InSAR studies were successful at identifying landfast ice, they relied on the 3-day repeat interval of the European Remote Sensing satellite (ERS-1) during its two ice phases from 1991-92 and 1993-94. There are currently no widely available complex SAR products at this repeat interval. However, with the launch of the Japanese Aerospace Exploration Agency's (JAXA's)

Table 1

Summary of different time-dependent techniques for identifying landfast sea ice.

\begin{tabular}{lllll}
\hline Authors & Technique & Sensors & $\begin{array}{l}\text { Spatial } \\
\text { resolution }\end{array}$ & $\begin{array}{l}\text { Time } \\
\text { interval }\end{array}$ \\
\hline $\begin{array}{c}\text { Mahoney et al. } \\
(2004,2006)\end{array}$ & $\begin{array}{l}\text { Spatial backscatter } \\
\text { gradient differencing }\end{array}$ & Radarsat SAR & $100 \mathrm{~m}$ & $\sim 20$ days \\
Giles et al. (2008) & $\begin{array}{l}\text { Boxcar image cross } \\
\text { correlation }\end{array}$ & Radarsat SAR & $200 \mathrm{~m}$ & $\begin{array}{l}1- \\
20 \text { days }\end{array}$ \\
Fraser et al. (2010) & $\begin{array}{l}\text { Mean-value temporal } \\
\text { compositing }\end{array}$ & MODIS & $2 \mathrm{~km}$ & 20 days \\
& & & & \\
\hline
\end{tabular}


L-band SAR PALSAR on board of ALOS in 2006, InSAR data in L-band has become more widely available, promising improved coherence over time spans of tens of days, thus enabling the mapping of landfast ice areas.

In addition to extraction techniques based on image interpretation, using the techniques of interferometry, glacier velocity has been successfully monitored in Greenland (Rignot \& Kanagaratnam, 2006) and Antarctica (Rignot et al., 2008). One of the main limitations of interferometric techniques applied to glaciers (Meyer, 2007) is temporal decorrelation of the SAR signals (Zebker \& Villasenor, 1992). The average loss of signal correlation over time is, among other factors, dependent on the wavelength of the applied system. Decorrelation is especially pronounced for data acquired in the higher signal frequencies of C-band and X-band while appearing reduced in low frequency data as provided by the L-band SAR used in this study. Many studies of InSAR coherence confirm a generally improved coherence in interferometric L-band SAR data (Rosen et al., 1996). Improved coherence in L-band over snow and ice areas is reported, e.g., by Lu et al. (2005).

\subsubsection{Interferometric coherence}

The complex coherence between two complex SAR images $u_{1}$ and $u_{2}$ is defined as

$\gamma=\frac{E\left\{u_{1} u_{2}^{*}\right\}}{\sqrt{E\left\{\left|u_{1}\right|^{2}\right\} E\left\{\left|u_{2}\right|^{2}\right\}}}$

where $\mathrm{E}\{$.$\} is the expectation value. A coherence value can be assigned$ to every pixel of an interferogram if the expectation values in Eq. (1) are known. Pixel coherence can be estimated from a suite of SAR observations through ensemble averaging. However, if only few repeated acquisitions are available, but ergodicity can be assumed, coherence can be estimated through spatial averaging over a uniform region. Under these assumptions, the maximum likelihood estimate of the coherence magnitude, $|\hat{\gamma}|$, can be derived using a small window $W$ centered around pixel $[i, k]$ (Seymour \& Cumming, 1994):

$$
|\hat{\gamma}[i, k]|=\frac{\left|\sum_{W} u_{1}[i, k] u_{2}^{*}[i, k]\right|}{\sqrt{\sum_{W}\left|u_{1}[i, k]\right|^{2} \sum_{W}\left|u_{2}[i, k]\right|^{2}}} .
$$

A reduction in the magnitude of the coherence estimate $|\hat{\gamma}|$, also called decorrelation, can be caused by several factors summarized in Eq. (3)

$|\hat{\gamma}|=\gamma_{\text {spatial }} \cdot \gamma_{\text {temporal }} \cdot \gamma_{\text {thermal }} \cdot \gamma_{\text {process }}$.

The term $\gamma_{\text {spatial }}$ in Eq. (3) corresponds to signal decorrelation caused by the incidence angle differences between the two acquisitions of an interferogram that is proportional to the perpendicular baseline $B_{\perp}$ separating the two SAR antennas. This difference in viewing angles results in a different ground reflectivity spectrum for each observation (Gatelli et al., 1994). Because spectral responses are not the same, the correlation of the two observations will be less than unity. This effect is often called spatial decorrelation. Due to the dependence on $B_{\perp}$, it is also known as baseline decorrelation. If pure surface scattering can be assumed, $\gamma_{\text {spatial }}$ can be modeled by

$\left|\gamma_{\text {spatial }}\right|=\left\{\begin{array}{cl}\frac{B_{\perp, \text { crit }}-B_{\perp}}{B_{\perp, \text { crit }}}, & \left|B_{\perp}\right| \leq B_{\perp, \text { crit }} \\ 0, & \left|B_{\perp}\right|>B_{\perp, \text { crit }}\end{array}\right.$

With $B_{\perp, \text { crit }}=-(W \rho \lambda \tan (\theta-\alpha)) / c$, the speed of light $c$, the bandwidth of the SAR signal $W$, the range to the object on ground $\rho$, the wavelength of the SAR signal $\lambda$, the incidence angle $\theta$, and the local surface slope $\alpha$, and removed from Eq. (3).

If the signal does penetrate into the surface, i.e. there is a significant volume scattering component, the effect of spatial decorrelation will be enhanced to $\left|\gamma_{\text {spatial }}\right|=\gamma_{\text {surface }} \cdot \gamma_{\text {volume }}$ where $\gamma_{\text {surface }}$ corresponds to Eq. (4). Both $\gamma_{\text {surface }}$ and $\gamma_{\text {volume }}$ depend on the signal wavelength and are less severe for L-band than they are for C-band.

$\gamma_{\text {thermal }}$, the thermal decorrelation factor, is related to the signal-tonoise ratio (SNR) of the data and can be described according to (Zebker \& Villasenor, 1992)

$\gamma_{\text {thermal }}=\frac{1}{1+{ }^{1} / \text { SNR. }}$

The SNR measured for a surface is dependent on surface roughness and its dielectric properties. Thus, it changes with signal wavelength and is often lower for lower frequencies. Due to the smoothness of the scattering interface and the associated low SNR, $\gamma_{\text {thermal }}$ can be low for very smooth young sea ice and is smaller for L- than C-band. Other examples of sea ice-related processes that lower SNR in SAR data are the frequent presence of melt water during spring and summer in the Arctic and snow load-related surface flooding events in Antarctic environments.

$\gamma_{\text {process }}$ describes processing-induced decorrelation effects that may stem from errors in co-registration, image interpolation, or spectral filtering. For this study, it is assumed that $\gamma_{\text {process }} \approx 1$.

$\gamma_{\text {temporal }}$ is the correlation factor associated with incoherent changes in the scattering medium between observations, and is in many cases the main driver for coherence loss in SAR interferometry. Mechanisms determining the amplitude of $\gamma_{\text {temporal }}$ over ice and snow surfaces include the movement of snow/ice particles on the surface due to wind, melting and refreezing processes, desalination of sea ice associated with aging processes, sea ice motion, deformation, or fracturing. Although temporal decorrelation generally increases with time and although attempts have been made to model the general trend of temporal decorrelation through empirical polynomial functions (e.g., Hoen and Zebker (2000)), a general model for $\gamma_{\text {temporal }}$ does not exist due to strong differences of $\gamma_{\text {temporal }}$ for different surface types and environmental conditions. However, Zebker and Villasenor (1992) developed a simplified model based on Gaussian-statistic motion of scattering elements that is useful to understand basic trends of $\gamma_{\text {temporal }}$. If decorrelation is dominated by random motion of scattering elements over time, and if it can be assumed that the changes in position of a scatterer are unrelated to its initial position and are characterized by independent Gaussian probability distributions, then $\gamma_{\text {temporal }}$ can be expressed by

$\gamma_{\text {temporal }}=\exp \left(-\frac{1}{2}\left(\frac{4 \pi}{\lambda}\right)^{2}\left(\sigma_{y}^{2} \sin ^{2} \theta+\sigma_{z}^{2} \cos ^{2} \theta\right)\right)$

with $\sigma_{y}^{2}$ being the variance of motion in horizontal direction and $\sigma_{z}^{2}$ the variance of motion in vertical direction. From Eq. (6) it can be seen that $\gamma_{\text {temporal }}$ is again dependent on $\lambda$ and is smaller for L-band than for C-band.

Most of the aforementioned decorrelation factors show a dependence on signal frequency (see Eqs. 4-6) and are, with the exception of $\gamma_{\text {thermal }}$, less severe for low frequency systems, e.g. for L-band. Therefore, L-band systems $(\lambda \approx 0.25 \mathrm{~m})$ are preferred over C-band $(\lambda \approx 0.05 \mathrm{~m})$ or $\mathrm{X}$-band $(\lambda \approx 0.03 \mathrm{~m})$ systems for monitoring natural environments and have been implemented with great success for many geodynamic studies. As landfast ice is per definition stationary over longer time spans, it is expected that temporal decorrelation in L-band is limited. Therefore, L-band InSAR coherence might provide a robust means for detection and delineation of the landfast ice extent. 
3.1.2. Statistical properties of coherence on landfast and moving ice

In order to verify the applicability of L-band InSAR for mapping landfast ice extent we performed an analysis of the average L-band coherence over landfast ice in 46 day ALOS PALSAR interferograms relative to the average coherence of non-stationary ice areas. To this end, InSAR pairs over several areas of interest and for several stages of the landfast ice season were processed to interferograms and interferometric coherence was derived. Based on independent knowledge of the landfast ice extent at the respective InSAR acquisition times, the coherence in landfast ice areas was compared to the coherence in areas of moving ice. Table 2 summarizes the parameters of the L-band ALOS PALSAR interferograms that were used in this analysis. All images used here were ALOS PALSAR Fine Beam Single-Polarization data sets with a swath width of $70 \mathrm{~km}$. The data were acquired from the data holdings of the Alaska Satellite Facility's Americas ALOS Data Node (AADN). Test sites include the area around Barrow, Alaska, and Alaska's Seward Peninsula. These two regions represent a broad range of sea ice conditions, with landfast and offshore ice at Barrow consisting of a mixture of level and deformed first- and multiyear ice representative of the marginal seas of the Arctic Basin. Ice along the Seward Peninsula is more representative of somewhat milder, dynamic ice regime of sub-Arctic seas.

Fig. 1a shows the coherence probability density functions (PDFs) for areas of moving ice (gray lines) and for landfast ice regions (black lines) for the interferograms listed in Table 1 (first interferogram: bold line; second: dashed line; third: dotted line; fourth: dash-dotted line). The coherence was calculated based on Eq. (2) from fullresolution single-look interferograms and using a $5 \times 5$ estimation window size. The $5 \times 5$ estimation window size was chosen as a compromise between spatial resolution, coherence estimation bias, and shape of the coherence PDF. Large window sizes reduce biases in coherence estimation and produce coherence PDFs with small standard deviation and Gaussian shape (Bamler \& Hartl, 1998). Both effects are favorable as they minimize the overlap of PDFs of different coherence regimes. However, large window sizes also reduce the spatial resolution of resulting coherence maps.

As expected, the coherence distributions of the moving sea ice samples show the typical pattern of total decorrelation with very consistent probability density functions and an average coherence of $\mu_{\gamma} \leq 0.08$. Total decorrelation is expected for drifting sea ice, as sea ice moves with speeds of tens of kilometers per day causing the ice surface captured in the interferometric partner images to change completely over a 46 day interval. Fig. 1a also indicates that the L-band coherence over landfast ice areas is significantly higher than the coherence over moving ice. While some variability can be observed between different realizations, all the samples presented here have significantly higher average coherence values of $\mu_{\gamma}=$ $\{0.2 ; 0.28 ; 0.31 ; 0.38\}$. It is worth noting that lowest coherence was observed in early winter, where low SNR as well as growth and deformation of the thin ice layer may be contributing to coherence degradation. As shown in previous studies (Sandwell et al., 2008),
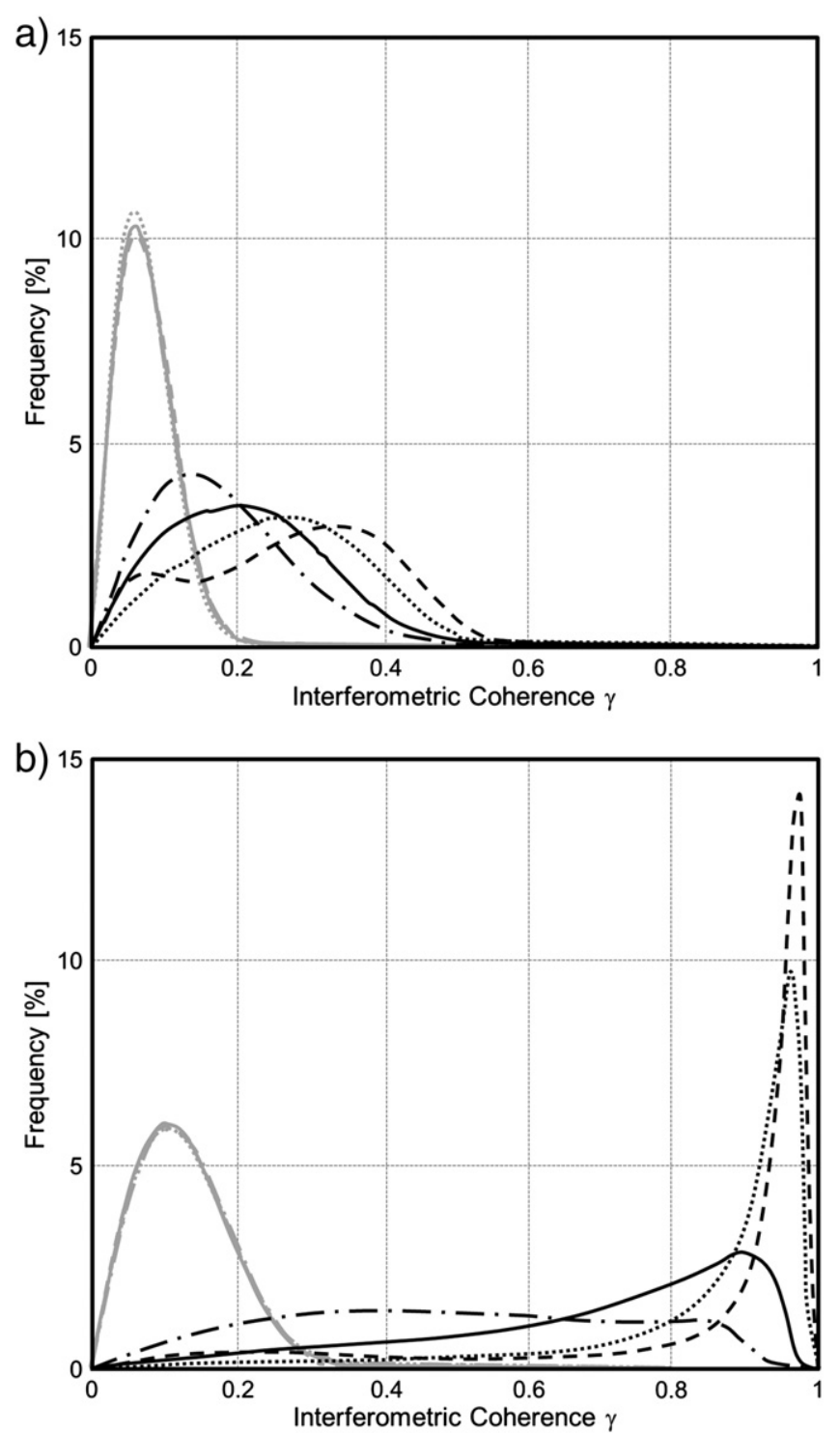

Fig. 1. a) Coherence PDFs for moving (gray lines) and stationary ice (black lines) calculated from full-resolution interferograms and using a $5 \times 5$ estimation window. PDFs are shown for the four interferograms listed in Table 1 (first interferogram: bold line; second: dashed line; third: dotted line; fourth: dash-dotted line). Significantly higher coherence is evident for stationary ice, yet PDFs overlap strongly; b) Coherence PDFs for drifting and stationary ice after an adaptive phase filter was applied. The separation of drifting and stationary ice PDFs appears greatly enhanced.

spatial phase pattern can be visually discerned and analyzed if the average coherence is $\mu_{\gamma} \geq 0.2$. Thus, in all of the presented test cases, the coherence over landfast ice areas is high enough to identify phase

Table 2

Image pairs used to study the coherence of landfast ice areas in 46 day ALOS PALSAR interferograms.

\begin{tabular}{|c|c|c|c|c|c|c|}
\hline & & \multicolumn{5}{|c|}{ Interferometric processing parameters } \\
\hline & & Orbit/frame & Resolution & Acquisition dates & $\Delta \mathrm{t}$ & $\mathrm{B}_{\perp}$ \\
\hline \multirow[t]{8}{*}{ Geographic location } & \multirow[t]{6}{*}{ Barrow, Alaska } & $10171 / 1430$ & Range: $9.4 \mathrm{~m}$ & $12 / 22 / 2007$ & 46 days & $910 \mathrm{~m}$ \\
\hline & & $10842 / 1430$ & Azimuth: $18.5 \mathrm{~m}$ & $02 / 06 / 2008$ & & \\
\hline & & $10842 / 1430$ & Range: $9.4 \mathrm{~m}$ & 02/06/2008 & 46 days & $630 \mathrm{~m}$ \\
\hline & & $11513 / 1430$ & Azimuth: $18.5 \mathrm{~m}$ & $03 / 23 / 2008$ & & \\
\hline & & $11265 / 1430$ & Range: $9.4 \mathrm{~m}$ & 03/06/2008 & 46 days & $570 \mathrm{~m}$ \\
\hline & & $11936 / 1430$ & Azimuth: $18.5 \mathrm{~m}$ & $04 / 21 / 2008$ & & \\
\hline & \multirow[t]{2}{*}{ Seward Peninsula, AK } & $10186 / 1320$ & Range: $9.4 \mathrm{~m}$ & $12 / 23 / 2007$ & 46 days & $950 \mathrm{~m}$ \\
\hline & & $10857 / 1320$ & Azimuth: $12.5 \mathrm{~m}$ & $02 / 07 / 2008$ & & \\
\hline
\end{tabular}


pattern, and both phase and coherence images can be used to identify and map landfast ice extent.

While this initial analysis verifies that landfast ice can be identified in interferometric coherence images, Fig. 1a also shows significant overlap between the coherence PDFs of moving and stationary ice. Hence, a simple pixel-based thresholding operator will produce misclassifications for pixels with coherence values close to the detection threshold. To improve the separation between landfast ice and background coherence, an additional adaptive phase filter is applied, whose filtering function is based on the local fringe spectrum. The applied filter, presented by Goldstein and Werner (1998), significantly reduces phase noise for areas with sufficiently reliable phase information, while high phase noise areas are minimally affected. Therefore its application maximizes the contrast between de-correlated and coherent areas in both the interferometric phase and coherence image and enhances the detectability of the landfast ice extent. The non-linear filter is described by an exponent $\alpha$ that determines the filter strength, with larger values leading to greater filtering. The application of this filter raises the coherence in landfast ice areas considerably, while the coherence PDFs of the decorrelated moving ice remain largely unchanged (see Fig. 1b). Fig. $1 \mathrm{~b}$ presents the coherence PDFs for the moving ice (gray lines) and landfast ice (black lines) samples after the application of the adaptive phase filter. As predicted, the PDFs of the moving ice samples changed only minimally, while the coherence over stationary ice increased dramatically. It is obvious that, after the phase filter was applied, the identification of landfast ice areas appears vastly improved and a statistical thresholding operation of L-band coherence images will be a useful first step in a landfast ice detection scheme.

In the following section, we will demonstrate that L-band InSAR is a convenient base layer for landfast ice detection in both manual and automatic detection procedures. While, for operational applications, landfast ice edge detection is currently performed manually, a proof of concept of an automated procedure for landfast ice delineation is presented that uses coherence information as a base layer in a work flow that adds in additional operators like morphological filters, patch size analysis, and linear feature extraction for robust landfast ice edge detection.

\subsubsection{Workflow for manual landfast ice edge extraction from InSAR}

With this section we want to introduce a standard workflow that can be employed for manual operational detection of the landfast ice edge. In particular, we want to emphasize that L-band InSAR provides base layers that are easy to read and understand, hence minimizing subjective operator-based extraction errors and easing the amount of required image interpretation.
The workflow for manual extraction, depicted in Fig. 2, is essentially a three-step procedure including data ordering, interferometric SAR processing, and GIS analysis. For ordering we take advantage of the data selection and ordering utilities provided by the Alaska Satellite Facility's User Remote Sensing Access (URSA) interface, which, in its latest edition, provides convenient tools for identifying InSAR pairs over an area of interest. These URSA tools are available to every ASF data user and can be readily used to identify InSAR data available in the ASF archives for any area on the globe. In a second step, an automated InSAR workflow is applied that takes interferometric partner images, processes them to interferograms, applies adaptive phase filters and geocodes coherence, phase, and amplitude images to a geographic projection of choice. The InSAR processing can be done with freely available community software tools such as the Repeat Orbit Interferometry Package (ROI_PAC) (Rosen et al., 2004). The end products of the InSAR processing chain are GeoTIFF images that can be easily imported into GIS software such as ArcGIS, for analysis by operators. For best analysis results and to aid image interpretation, the operator is provided with a composite image that includes both interferometric coherence and interferometric phase information. Additional land masking is applied to improve orientation and clarity.

\subsubsection{A workflow for automated landfast ice edge extraction from InSAR}

Although the manual workflow presented in Section 3.1.3 has proven to be quick and robust, a routine mapping of Arctic landfast ice extent over large areas would still benefit from an automated or semi-automated workflow to reduce manual labor and speed up the processing flow. Below, we introduce an approach to automate landfast ice extraction from L-band InSAR data and illustrate its performance in an example.

Although the separation of stationary and moving ice areas in the coherence image is significant, the coherence PDFs depicted in Fig. 1a still show overlap, causing errors in a pixel-by-pixel threshold-based landfast ice detection. To provide robust landfast ice detection, we therefore implemented a processing chain that combines a statistical constant-false-alarm-rate (CFAR) classification with subsequent spatial image processing steps. Within the multi-step procedure, a final classification decision is made based on the following characteristics: statistical coherence thresholding, morphological image analysis, image segmentation and patch size analysis, final morphological closing procedure, and outline extraction (see Fig. 3 for an example). In the following sections we explain the motivation and process behind the individual processing steps. This explanation is assisted by a processing example of an L-band InSAR scene covering part of the Seward Peninsula, Alaska (see Fig. 3). Starting from the

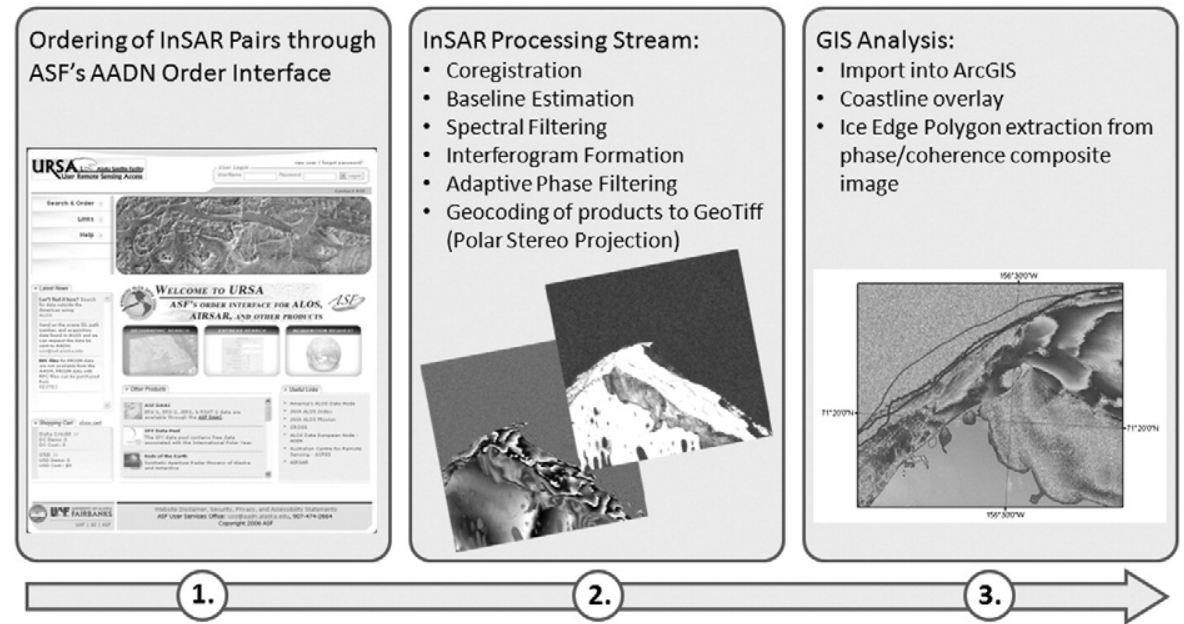

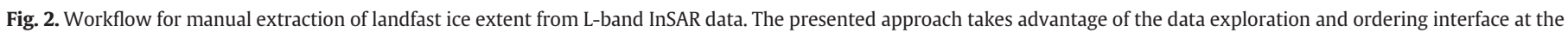
Alaska Satellite Facility but can be adapted to any other interface if required. 

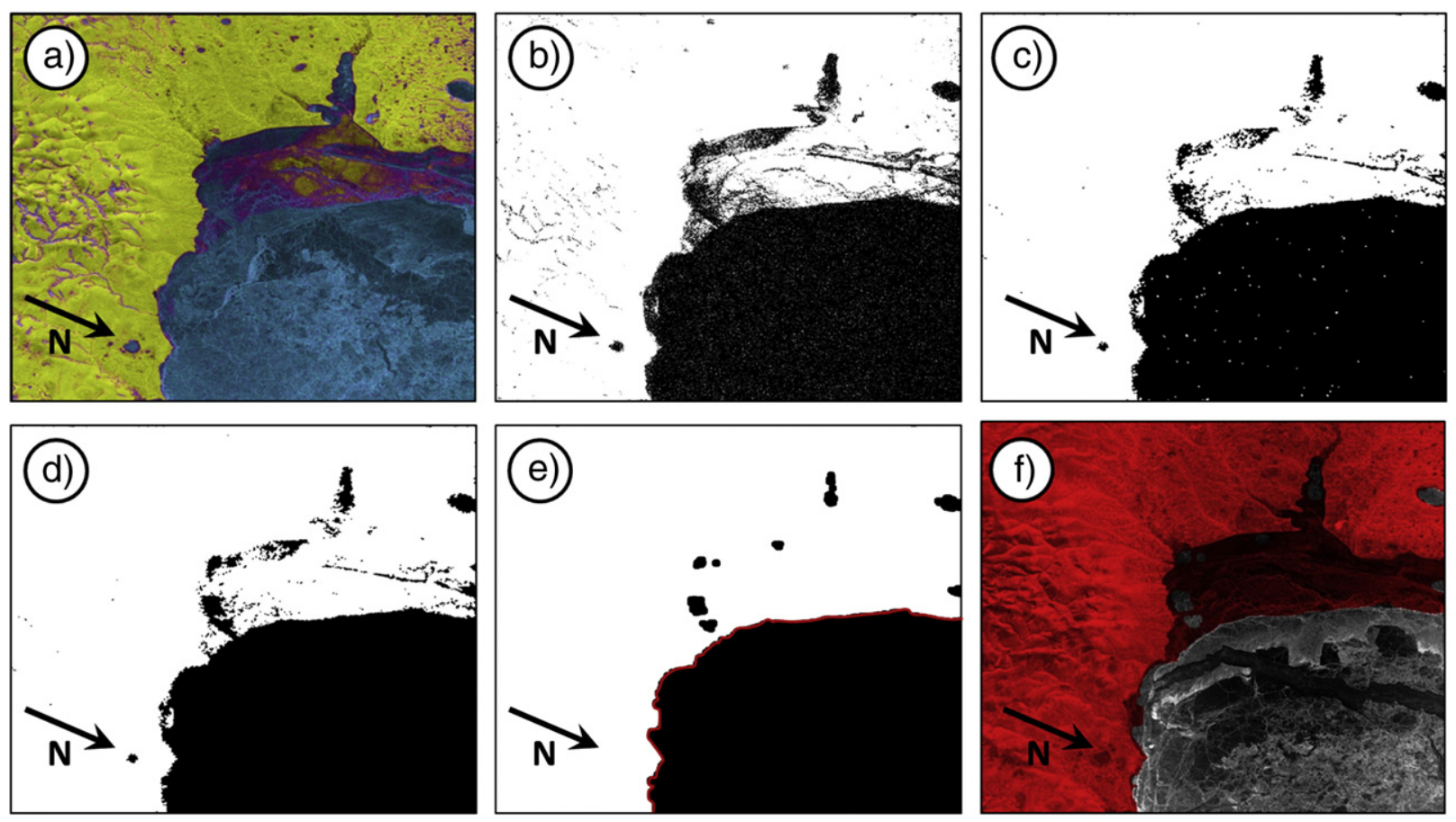

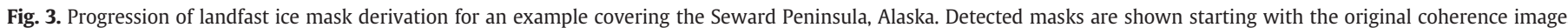

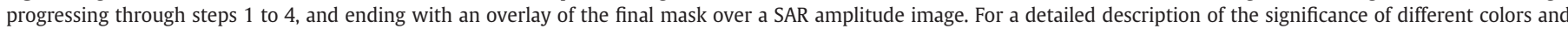
shading, please see text.

interferometric coherence image (Fig. 3a), the results of the individual processing steps are illustrated to provide a first visual assessment of the extraction quality.

3.1.4.1. Step 1: Pre-classification by statistical coherence thresholding. As explained above, areas of moving sea ice will decorrelate in 46-day ALOS PALSAR interferograms, such that the statistical properties of the interferometric coherence over drifting sea ice areas is consistent and predictable (see gray lines in Fig. 1). This allows application of CFAR detection methodology for pre-classifying interferograms into landfast and drifting ice classes. In CFAR classifiers, the classification threshold can be set statistically to yield constant and pre-defined false detection probabilities $P_{f a}=\alpha$, where $\alpha$ corresponds to a predefined acceptable false alarm rate. Therefore, CFAR classifiers have the advantage of producing statistically consistent results as they do not require a manual and somewhat arbitrary choice of the detection threshold. More information in CFAR classification methods can be found in Gandhi and Kassam (1988); Meyer et al. (2006).

For the application at hand we empirically determined a false alarm rate of $P_{f a}=0.1$ to be most suitable for pre-classifying the data into candidate classes. Fig. 3b, shows the coherence mask created using the CFAR detection step. Areas in white indicate areas classified as landfast ice. At this stage, this class also contains all landmasses in the image, which are masked for final landfast ice area assessment after landfast ice edge extraction. Land masking was performed by overlaying coastline information onto the geocoded SAR products. The accuracy of the land masking approach depends on the geocoding quality of the SAR data and the accuracy of the coastline information. The geocoding accuracy of PALSAR data can be quantified with $\sim 10 \mathrm{~m}$ (Rosenqvist et al., 2007). The coastline information used in this study was digitized from USGS 1:63,360 topographic maps ranging in date from 1950's to 1990's. The quality of the extracted coastline is not precisely know due varying to coastline retreat that was observed along the Alaskan Arctic coast. As this study focuses on a relative analysis of landfast ice detection methods, absolute errors introduced by uncertainties in the coastline location are of lesser importance.
The initial CFAR classification covers most of the landfast ice areas but leaves holes in some isolated decorrelated regions both inland and offshore. The decorrelated patches are partly caused by temporal decorrelation on not-yet-frozen fresh water lakes and by low signalto-noise ratios on some very low-backscatter sea ice patches. In addition to these holes, the mask also shows a larger amount of isolated false positive detections in areas of drifting ice (white speckles in lower right part of Fig. 3b). The number of false detections is defined by our choice of $P_{f a}=0.1$. As the false positives are isolated pixels rather than clusters, they can be easily removed in subsequent morphological filtering steps.

3.1.4.2. Step 2: Morphological operations. In an intermediate step, morphological filters (median, erosion and dilation filters) are used to fill small holes in the existing mask and to remove small patches of false detections, which originate from the speckle pattern in the SAR data (see Fig. 3c). This leads to a reduction of false positives and closes some holes in the landfast ice class. Background information on the morphological filters applied in this study can be found in Haralick and Shapiro (1992).

3.1.4.3. Step 3: Patch size analysis. After the morphological filtering the mask is segmented into connected sub-regions, each of which is assumed to cover parts of the total landfast ice area. The segmentation process follows an approach presented by Haralick and Shapiro (1992). From an analysis of several segmentation results we have empirically determined that patches of false positives cover less than $500 \mathrm{~m}^{2}$ per piece, and segments smaller than this are rejected. The remaining segments are combined and handed over to the next processing step. The improvement in landfast ice mask accuracy can be seen in Fig. 3d, where many of the false alarms in the drifting ice regions have been discarded.

3.1.4.4. Step 4: Creation of closed outline and outline tracing. A morphological closing procedure is applied to create a closed outline for the generated mask. Closing is performed using a flat linear structuring element. To fix the orientation of these linear elements, 
gradients are calculated from the mask and their local orientation is extracted (Haralick \& Shapiro, 1992). This last processing step provides a closed mask whose outline can easily be traced using line extractors. In our case, linear features are extracted in a first step. The individual line segments are then connected and tested for closed loops. Closed loops are rejected as they do not represent the landfast ice edge. The final extracted line is shown in Fig. 3e. Fig. 3f also shows the final landfast ice mask superimposed on a SAR amplitude image to provide a visual for a first validity test of the mask. A quantitative accuracy analysis of landfast ice extent extracted from L-band InSAR data is provided in Section 4.

\subsection{Description of reference techniques}

To validate the results of the interferometric SAR analysis, we use a reference technique based on a temporal analysis of triplets of consecutive C-band Radarsat-1 ScanSAR images spanning a period of approximately 20 days as described by Mahoney et al. (2004). In essence, the technique calculates the net difference between the three images to identify those parts of the image that correspond to moving ice. Giles et al. (2008) used a slightly different approach relying on a boxcar cross-correlation between consecutive images to identify ice motion. Though largely successful, the task is complicated by changes in backscatter unrelated to ice motion such as those caused by differences in look angle and environmental changes at the ice surface. Areas of low backscatter, commonly found within landfast regions, give rise to lower signal to noise ratios and create further difficulties in using cross-correlation techniques. Mahoney et al. (2004) found that the most stable features of the imagery were the linear, high backscatter regions corresponding to ridges that play an important part in anchoring the landfast ice. To accentuate these features, each image in the triplet was filtered with two independent, orthogonal directional filters, which effectively calculated the horizontal and vertical backscatter gradient fields. The net difference calculation was then carried out on the resulting gradient images:

$\Delta_{n e t} \nabla_{H}=\left|\nabla_{H} \Phi_{1}-\nabla_{H} \Phi_{2}\right|+\left|\nabla_{H} \Phi_{1}-\nabla_{H} \Phi_{3}\right|+\left|\nabla_{H} \Phi_{2}-\nabla_{H} \Phi_{3}\right|$

where $\Phi_{1}, \Phi_{2}$, and $\Phi_{3}$ are three consecutive grayscale images and $\nabla_{\mathrm{H}}$ is the horizontal gradient component. The net difference of the vertical gradient components, $\nabla_{\mathrm{V}}$, is calculated in a similar manner. The overall magnitude of the gradient difference is calculated from the Pythagorean sum of the two gradient difference components:

$\Delta_{\text {net }} \nabla_{\text {mag }}=\sqrt{\left(\Delta_{\text {net }} \nabla_{H}\right)^{2}+\left(\Delta_{\text {net }} \nabla_{V}\right)^{2}}$.

Fig. 4 shows an example of using this technique to identify landfast ice. Fig. 4(a-c) shows three parent images spanning a 20-day period. Fig. $4(\mathrm{~d}-\mathrm{f})$ shows the $\Delta_{\text {net }} \nabla_{\mathrm{H}}, \Delta_{\text {net }} \nabla_{\mathrm{V}}$, and $\Delta_{\text {net }} \nabla_{\text {mag fields. Landfast ice }}$ is characterized by dark regions of low $\Delta_{\text {net }} \nabla$ typically bounded by bright linear regions of high $\Delta_{\text {net }} \nabla$. Note however, that in the parent imagery (Fig. $4 a-c$ ) the landfast ice is comprised of both high and low
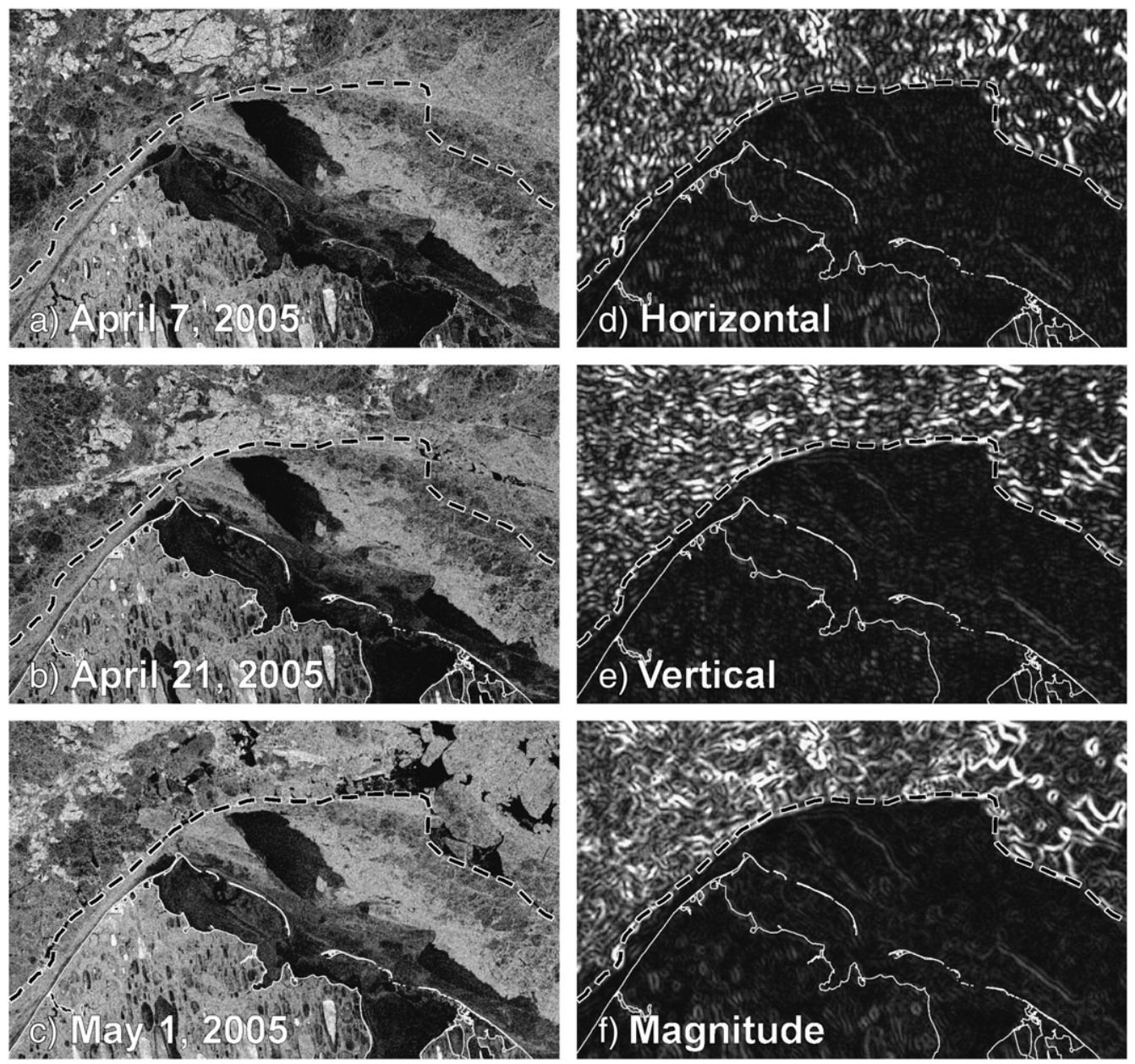

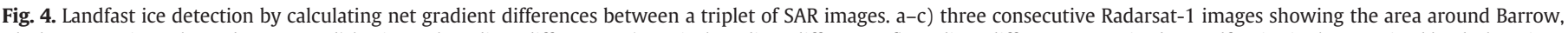

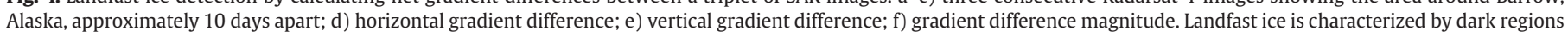
in $\mathrm{d}-\mathrm{f}$, often bounded by bright linear regions. 
backscatter regions and the seaward edge does not coincide with a strong boundary. The seaward landfast ice edge is shown as dashed line. Although Mahoney et al. (2006) had some success applying an automated algorithm to the gradient difference images to identify landfast in mid-winter, in general the technique has to rely on visual interpretation in conjunction with the three parent images. In this approach, the gradient difference images are used as visual aids, reducing the subjectivity inherent in visual interpretation.

\section{Validation of mapping results}

For evaluating the performance and reliability of landfast ice detection from L-band InSAR data, several SAR interferograms were processed over two test sites, the area around Point Barrow, Alaska, and the coastline of the Seward Peninsula, Alaska. These two test sites were selected to cover different climatic zones of the Arctic environment, with longer, colder, and more stable landfast ice conditions in Barrow. Also, the test sites offer varying conditions in terms of general ice drift, wind exposure, and ocean currents, all factors that influence landfast ice development and stability. The InSAR data sets shown in the following were chosen to represent different conditions throughout the landfast ice season in order to enable an assessment of performance as a function of landfast ice age and thickness, and dependent on changing weather conditions. The Barrow, Alaska examples were acquired later in the landfast ice season at a time where both the weather conditions and the landfast ice itself were rather stable. The data sets over Seward Peninsula, Alaska stem from a time early in the landfast ice season with more variable climatic conditions and less stable landfast ice extent. Both sets of examples were randomly chosen from all data covering the respective season at the respective geographic location and are representative for the total bulk of available data.

Radarsat-1 ScanSAR data was processed using the techniques presented in Section 3.2 to provide reference data for evaluating the relative performance of the L-band InSAR based method. To minimize errors in the reference data, the landfast ice edge was extracted manually from the Radarsat-1 ScanSAR imagery processed to gradient difference images. For mapping the landfast ice edge from L-band InSAR, the automated workflow described in Section 3.1.4 was used. In the following, relative performance analyses are presented for several InSAR pairs over both test sites to provide proof for the consistency, suitability, and accuracy of the presented methods.

\subsection{Approach for data harmonization and comparison}

To facilitate a comparison of landfast ice extents derived from L-band InSAR and the reference technique, the temporal sampling of the individual data sources has to be unified. Due to the long repeat interval of currently available L-band SAR data, L-band InSAR-derived landfast ice edges correspond to sea ice areas that remained stable over a time span of 46 days. Due to a shorter repeat interval of the sensor Radarsat- 1 and because of the large spatial coverage of Radarsat-1 ScanSAR images and the resulting large overlap of neighboring scenes, the reference technique defines landfast ice as sea ice that remained stationary over a time interval of about 20 days. Hence, the landfast ice extent mapped by both techniques follows different physical definitions, and an approach has to be defined to transform derived results to a common temporal sampling.

As explained in Section 2, the extent of landfast ice detected by the different methods decreases with the length of the observation window. For InSAR data, only ice that remained stationary over an entire 46-day interval will be classified as landfast ice, corresponding to the minimum landfast ice extent during the observation period. To ensure intercomparability, all landfast ice edges extracted by the reference approach within a 46-day period are compared and their minimum extent is extracted manually as the representative ice edge for that period. An
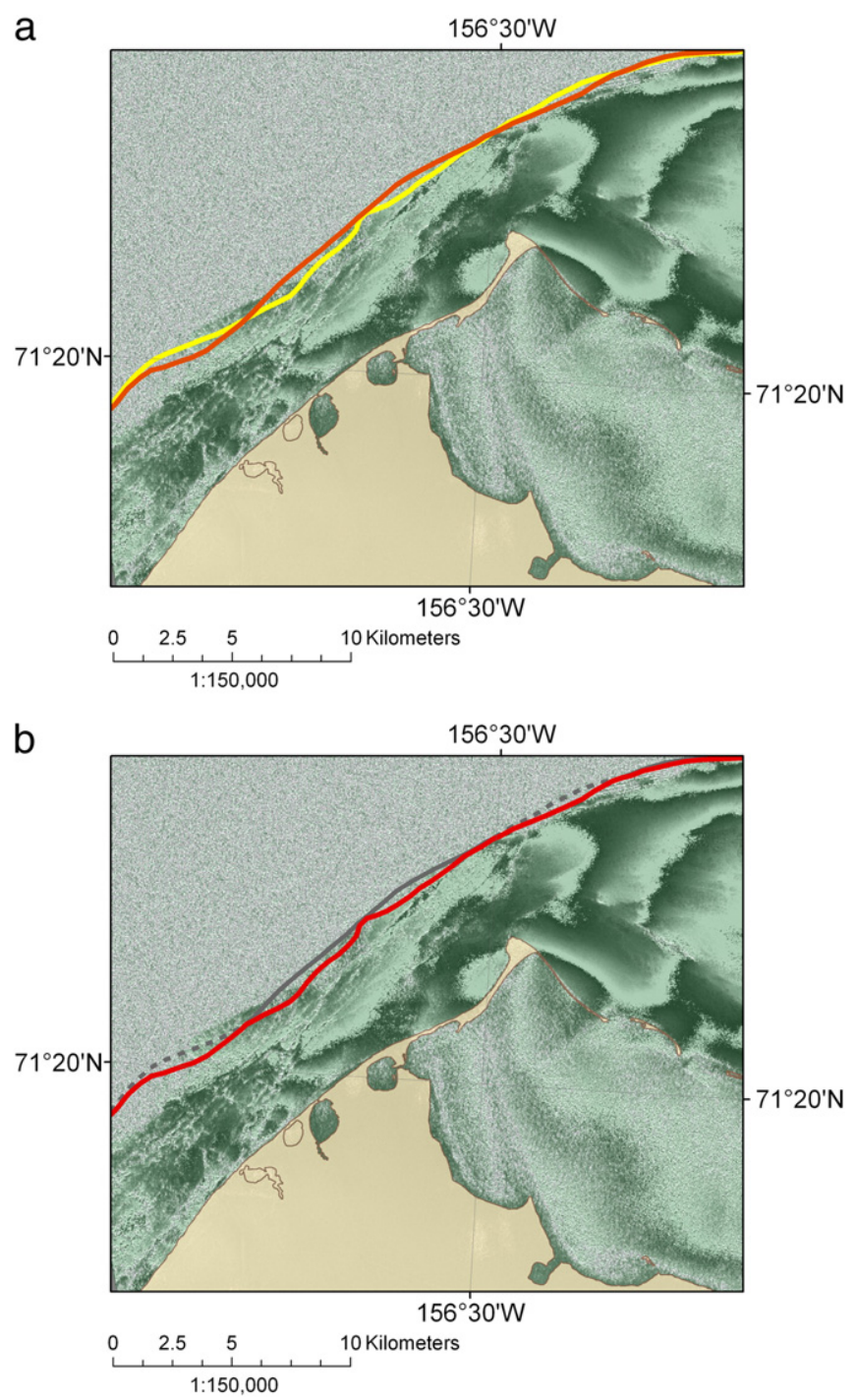

Fig. 5. a) Landfast ice edges extracted from Radarsat- 1 ScanSAR data spanning a time interval of 20 days and showing the variability of landfast ice extent over time; b) Extracted minimum landfast ice extent for a 46-day time period used for comparison to InSAR-based landfast ice outlines. Acquisition dates for this interferogram are listed under "Interferogram B" in Table 3.

example for the extraction of the 46-day reference landfast ice edge from all 20-day outlines is shown in Fig. 5 for an area near Barrow, Alaska, where Fig. 5a shows the original 20-day reference outlines as colored lines on top of a phase filtered L-band interferogram. In Fig. 5b the minimum ice extent has been extracted from the set of 20-day edges. A visual comparison of the coherent area in the SAR interferogram and the 46-day reference ice edge shows good agreement.

\subsection{Application to test area near Barrow, Alaska}

\subsubsection{Available datasets}

An overview of the Radarsat- 1 and ALOS PALSAR data sets used for the area of Barrow, Alaska is shown in Table 3. Out of all available SAR data, two representative interferograms ( $A$ and $B$ in Table 3 ) were selected for a demonstration of the performance of InSAR-based landfast ice mapping. For the periods covered by both interferograms, four Radarsat-1 ScanSAR acquisitions were available (see Table 3, left side), from which two 20-day landfast ice edges were derived using the reference technique. 
Table 3

Data sets used for a relative performance analysis of InSAR-based landfast ice mapping and reference technique.

\begin{tabular}{|c|c|c|c|c|c|c|c|c|}
\hline & \multicolumn{4}{|c|}{ L-band InSAR data } & \multicolumn{4}{|c|}{ Radarsat- 1 data } \\
\hline & Orbit/frame & Acquisition dates & $\Delta \mathrm{t}$ & $\mathrm{B}_{\perp}$ & Orbit/frame & Acquisition dates & & \\
\hline \multirow[t]{4}{*}{ Interferogram A } & $10842 / 1430$ & $02 / 06 / 08$ & 46 days & $630 \mathrm{~m}$ & $63986 / 273$ & 02/16/08 & & \\
\hline & & & & & $64129 / 273$ & $02 / 27 / 08$ & 18 days & \\
\hline & & & & & $64268 / 273$ & $03 / 05 / 08$ & & 17 days \\
\hline & $11513 / 1430$ & $03 / 23 / 08$ & & & $64529 / 273$ & $03 / 15 / 08$ & & \\
\hline \multirow[t]{4}{*}{ Interferogram B } & $11265 / 1430$ & 03/06/08 & 46 days & $570 \mathrm{~m}$ & $64386 / 273$ & $03 / 15 / 08$ & & \\
\hline & & & & & $64529 / 273$ & $03 / 25 / 08$ & 20 days & \\
\hline & & & & & $64672 / 273$ & $04 / 04 / 08$ & & 18 days \\
\hline & $11936 / 1430$ & $04 / 21 / 08$ & & & $65058 / 273$ & $04 / 12 / 08$ & & \\
\hline
\end{tabular}

\subsubsection{Performance analysis}

From the original gradient difference image-based outlines, covering a time span of $\sim 20$ days each, a representative reference outline for comparison to the SAR interferograms was derived following the approach presented in Section 4.1. This derived reference outline was then compared to InSAR-based landfast ice

a

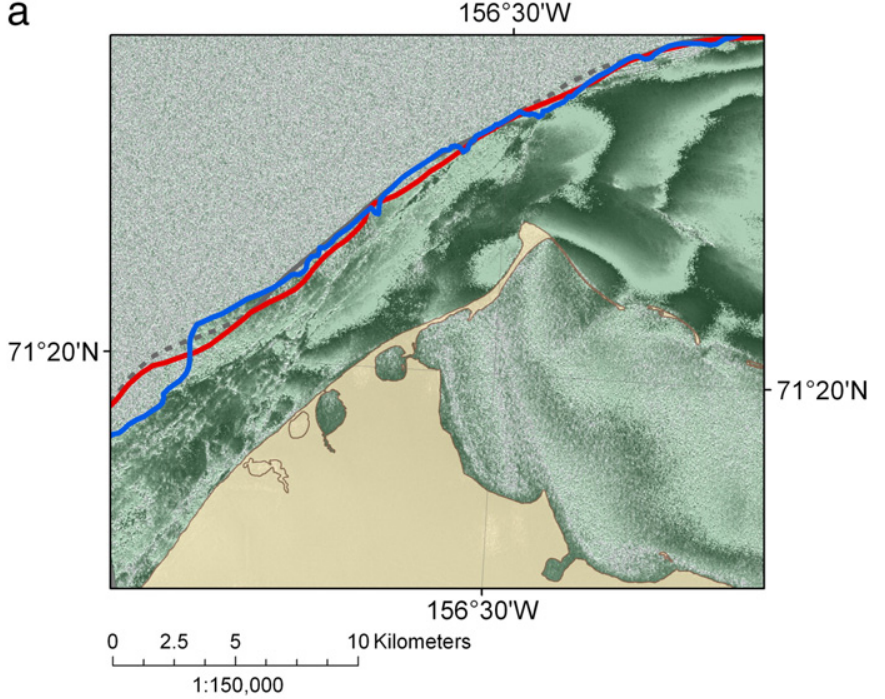

b

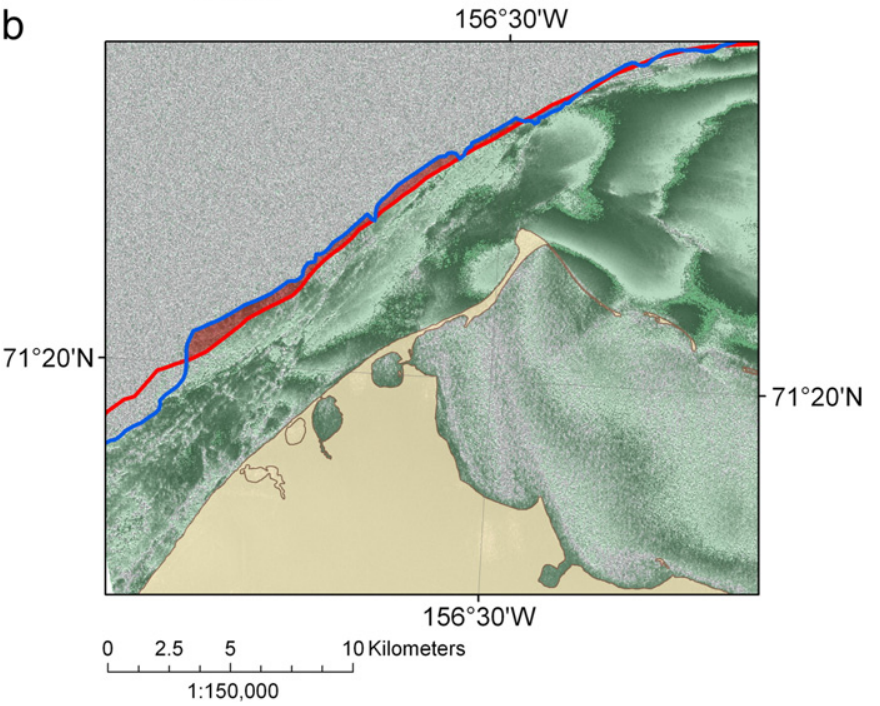

Fig. 6. a) Reference landfast ice edge in red compared to InSAR-based landfast ice edge in blue derived from interferogram B (Table 3); b) differences in landfast ice area between the two techniques. Red areas correspond to a relative underestimation by reference technique; blue area shows relative underestimation by InSAR-based technique. edges for an evaluation of relative performance. This comparison has been carried out for both interferograms A and B (see Table 3). Fig. 6 shows a segment of interferogram $B$ to showcase the comparison procedure. In Fig. 6a the reference outline and the InSAR-derived outline are projected onto interferogram $B$ as red and blue lines, respectively. A first comparison of these lines indicates that the two methods produce very comparable results.

Fig. 6b shows the results of a quantitative comparison between landfast ice areas extracted by the two techniques. Differences in coverage are classified into two classes: i) reference extent smaller than InSAR-based extent (red areas in Fig. 6b), and ii) reference extent larger than InSAR-based extent (blue regions in Fig. 6b). Regions of coherence in the interferograms must correspond to areas that remained stationary over the entire 46 day interval. Red segments therefore indicate underestimation of landfast ice extent by the reference technique. On the other hand, blue areas indicate regions that did not remain coherent over the 46-day interval and yet remained stationary according to the reference technique. Reduced coherence, and therefore an underestimation of landfast ice area by InSAR-based techniques, can appear in regions dominated by very smooth young sea ice, whose low backscatter gives rise to poor SNR. A relative comparison of extracted landfast ice areas will provide insight into the relative performance of the applied methods. While we are lacking accurate, dedicated ground-truth information, a coastal radar covering much of the area shown in Fig. 6 (Druckenmiller et al., 2009) indicates ice to be stable, though varying in backscatter strength, throughout the time period covered by interferogram $B$.

An areal analysis of relative extraction errors is presented in Fig. 7 for interferogram B spanning March 3-April 21, 2008. The interferogram together with reference and InSAR-derived landfast ice edge are presented in Fig. 7a. Areal differences between the outlines are analyzed in Fig. 7b where the entire outline is broken up into 20 segments of positive and negative area differences for which statistical parameters were derived. As before, negative (red) segments indicate relative underestimation by the reference technique while positive (blue) segments indicate a relative underestimation of landfast ice extent by the InSAR-based approach. From the visual representation in Fig. 7a as well as the statistical analysis in Fig. 7b it is evident that both techniques provide very consistent results with landfast ice area differing by only $\Delta a \approx 0.5 \mathrm{~km}^{2}$ over a coastline length of $95 \mathrm{~km}$. In a relative comparison, areal biases are slightly lower for the new InSAR-based method confirming its suitability for the task of landfast ice mapping.

Results for the interferogram A, spanning February 6-March 23, 2008, (see Table 3) are presented in Fig. 8. While this example also demonstrates generally consistent results from both methods, it reveals some minor but important differences, in particular at the center of the scene where the coherence image is significantly underestimating landfast ice extent relative to the reference technique (see blue area in Fig. 8a), limiting the detected landfast ice area to a narrow ice bridge. For a statistical comparison of the techniques two tables are shown in Fig. 8b and c. The first one (Fig. 8b) presents an analysis of areal differences based on all segments along the 


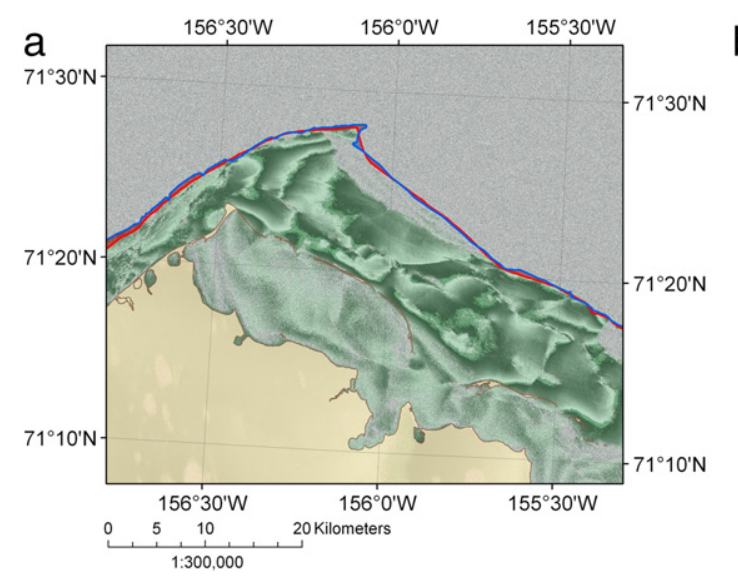

\begin{tabular}{lr}
\hline \multicolumn{2}{c}{ Statistical Parameters $\left(\mathrm{km}^{2}\right)$} \\
\hline Mean & -0.52 \\
Standard Deviation & 1.29 \\
Minimum & -4.61 \\
Maximum & 1.38 \\
\hline Sum Positive & 2.97 \\
\hline Sum Negative & -13.46 \\
\hline Number of Segments & 20 \\
\hline
\end{tabular}

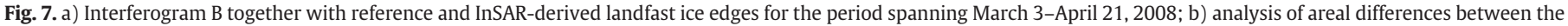
outlines where the entire outline is broken up into 20 segments of positive and negative area differences.

analyzed part of the coastline, indicating a significant relative underestimation of ice area by $\Delta a \approx 3.25 \mathrm{~km}^{2}$ committed by InSARbased mapping. As this difference is largely caused by one segment, a second table is added (see Fig. 8c) to analyze the relative performance of the techniques outside of this anomalous region. This second comparison shows very little difference between the techniques $\left(\Delta a<0.15 \mathrm{~km}^{2}\right)$ and verifies their general comparability.

To understand the observed differences in Fig. 8 we conducted a closer analysis of both a time series of Radarsat-1 ScanSAR scenes covering this time span and the ALOS PALSAR imagery contributing to the L-band interferogram. This detailed inspection showed two main features contributing to extraction errors: 1) variation of the landfast ice edge over the 46 day period introduced by hinging motion of parts of the ice close to the shore (see Fig. 9a and b), and 2) very low radar backscatter cross-section for a part of the landfast ice identified as area "A" in Fig. 9b. Fig. 9a shows four landfast ice edges extracted by the reference technique together with their respective time intervals. The evolution of the landfast ice edge is shown by lines overlaid on a superposition of a Radarsat-1 ScanSAR scene and the ALOS PALSAR interferogram. Note that the lines were derived using additional SAR data outside of the 46-day period of the interferogram.

From Fig. 9a it can be seen that the landfast ice extent varied extensively especially in areas to the east of the coherent ice bridge. This strong variation is caused by a hinging motion of large parts of the landfast ice area between the beginning of February and the middle of March, 2008. The rotational motion was centered about a point to the north-east of Point Barrow, causing a lead to open up. The width of this lead increases with distance from Point Barrow and reaches a maximum of about two miles at the eastern edge of the coastline segment shown in Fig. 9a. The affected landfast ice patch is indicated in Fig. 9b where the dashed white line represents the location of the ice before the hinging motion, while the solid white line shows its location after the displacement occurred. This motion led to an underestimation of landfast ice extent by both the reference technique and the InSAR-based method (see also Fig. 9a as a reference). The decorrelation of the InSAR phase was due to motion-induced co-registration mismatch. Additional coherence loss that can be observed to the West of the area affected by ice motion (area "A" in Fig. 9b) is caused by a very low SNR on smooth ice patches. The combined effect of both factors gave rise to the underestimation of landfast ice extent in this example.

\subsection{Application to test area Seward Peninsula, Alaska}

\subsubsection{Available datasets}

As stated above, the northern Seward Peninsula, Alaska has been added as a second test site to increase the level of generality of the

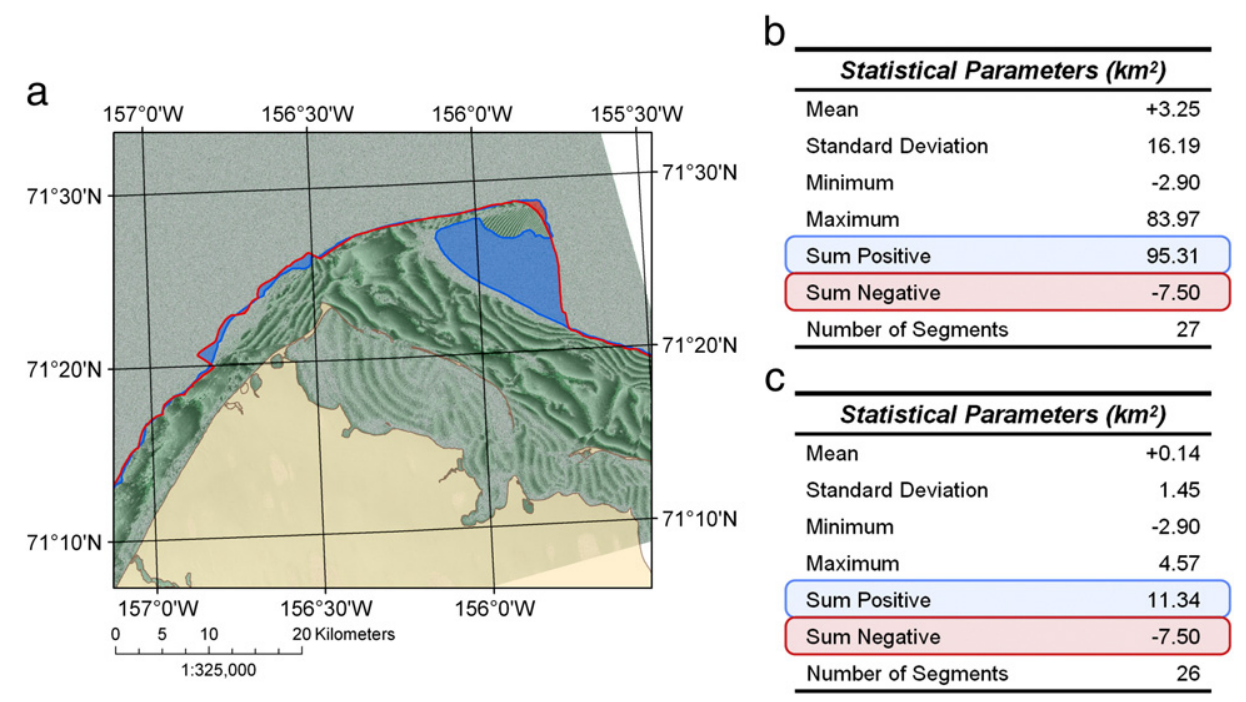

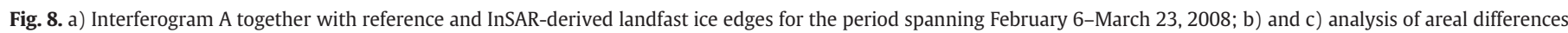
between the outlines. In c), the anomalous region of large areal differences is ignored in the statistics. 


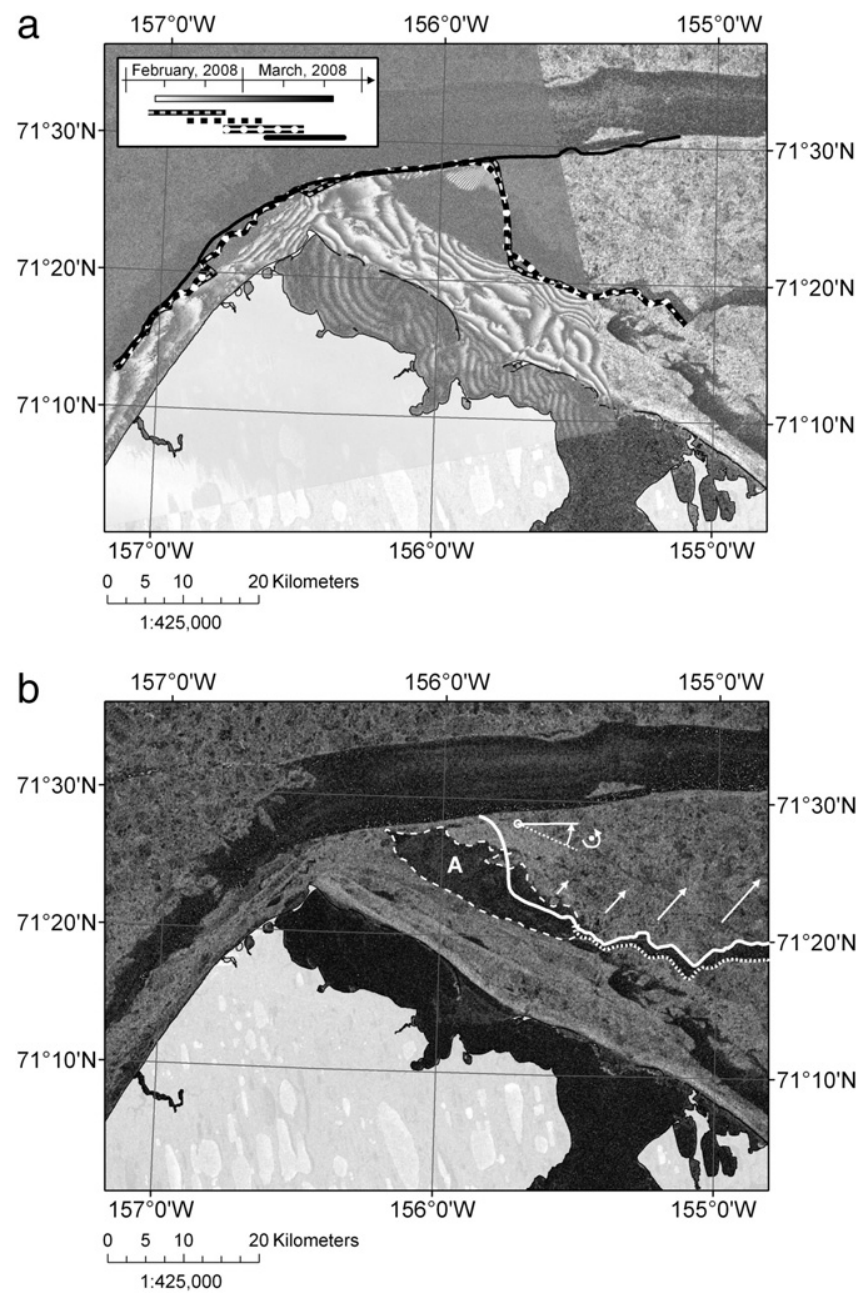

Fig. 9. a) The interferogram from Fig. 8a shown with four landfast ice edges identified using the reference technique spanning a similar time period (time spans indicated by inset at top left); b) an analysis of a time series of Radarsat-1 ScanSAR images revealed a hinging motion of large parts of the landfast ice area as the main cause for errors in landfast ice estimates by both the reference and the InSAR-based techniques. Area " $A$ " marks a low backscatter region causing SNR-based coherence loss.

derived performance measures. The Seward Peninsula is characterized by shorter landfast ice seasons governed by more dynamic environmental conditions. Also, drift patterns and velocities of drifting sea ice differ compared to test site Barrow, Alaska, resulting in different landfast ice dynamics. An overview of the Radarsat- 1 and ALOS PALSAR data sets used for Seward Peninsula, Alaska is shown in Table 4. Two neighboring InSAR frames of the early landfast ice season are shown along with several Radarsat-1 ScanSAR acquisitions for both data sets (see, Table 4 left side).

\subsubsection{Performance analysis}

Results for both neighboring InSAR frames are presented in Fig. 10 indicating a high general consistency between the results of the applied methods. As in the previous examples, reference outline and InSAR-derived outline correspond very well for most areas. Larger differences occur only along the northern tip of the captured area of the Seward Peninsula, where changes of the sea ice drift field and ocean currents result in highly dynamic landfast ice conditions. Hence, for the statistical comparison of the techniques (see Fig. 10b), these anomalous features were ignored. The areal differences between both techniques are presented in Fig. 10b and are again very small, with an average difference of only $\Delta a \approx 0.2 \mathrm{~km}^{2}$. Therefore, both test sites show a high consistency between the results provided by both detection techniques and suggest the suitability and sufficient performance of L-band InSAR for automated landfast ice mapping.

\section{Discussion on additional benefits and data coverage}

\subsection{INSAR phase information for the analysis of ice stability}

In the previous sections we have provided evidence that L-band InSAR coherence can be a reliable and easily interpretable data source for automated and semi-automated detection of landfast ice extent. Besides using InSAR coherence for landfast ice detection, however, an analysis of the interferometric phase of landfast ice areas can provide additional insight into landfast ice stability and potential deformation processes. This information is of great value in the context of coastal ice use and ice operations (Eicken et al., 2009) and is not accessible through other landfast ice mapping techniques with large areal coverage. In SAR interferograms of landfast ice regions, areas of uniform fringe pattern indicate landfast ice that has moved as a rigid body and the pattern and density of the fringes can be used to determine the nature and amount of any motion (e.g. translation, rotation or shear) (Lang, 2003). Discontinuities in the phase pattern can also be used to infer the location of cracks and individual ice floes comprising the landfast ice. As the InSAR phase is only sensitive to the line-of-sight component of the three-dimensional motion vector, it is often useful to augment the observed interferometric phase patterns with high resolution, sub-pixel accurate (real value and complex) cross-correlation techniques, which can quantify meter-scale motion in two dimensions.

An example of the amount of information that can be extracted from InSAR data is presented in Fig. 11. An interferogram of landfast ice near Barrow, Alaska in Fig. 11a shows isolated regions of high

Table 4

Data sets used for a relative performance analysis of InSAR-based landfast ice mapping and reference technique.

\begin{tabular}{|c|c|c|c|c|c|c|c|c|c|}
\hline & \multicolumn{4}{|c|}{ L-band InSAR data } & \multicolumn{5}{|c|}{ Radarsat-1 data } \\
\hline & Orbit/frame & Acquisition dates & $\Delta \mathrm{t}$ & $\mathrm{B}_{\perp}$ & Orbit/frame & Acquisition dates & & $\Delta \mathrm{t}$ & \\
\hline \multirow[t]{5}{*}{ Interferogram C } & $10186 / 1330$ & $12 / 23 / 07$ & 46 days & $950 \mathrm{~m}$ & $63343 / 286$ & $01 / 02 / 08$ & & & \\
\hline & & & & & $63486 / 286$ & $01 / 09 / 08$ & 14 days & & \\
\hline & & & & & $63586 / 286$ & $01 / 16 / 08$ & & 17 days & \multirow{3}{*}{17 days } \\
\hline & & & & & $63829 / 286$ & $01 / 26 / 08$ & & & \\
\hline & $10857 / 1330$ & $02 / 07 / 08$ & & & $63929 / 286$ & $02 / 02 / 08$ & & & \\
\hline \multirow[t]{5}{*}{ Interferogram D } & $10186 / 1320$ & $12 / 23 / 07$ & 46 days & $952 \mathrm{~m}$ & $63343 / 286$ & $01 / 02 / 08$ & & \multirow{4}{*}{17 days } & \multirow{5}{*}{17 days } \\
\hline & & & & & $63486 / 286$ & $01 / 09 / 08$ & 14 days & & \\
\hline & & & & & $63586 / 286$ & 01/16/08 & & & \\
\hline & & & & & $63829 / 286$ & $01 / 26 / 08$ & & & \\
\hline & $10857 / 1320$ & $02 / 07 / 08$ & & & $63929 / 286$ & $02 / 02 / 08$ & & & \\
\hline
\end{tabular}




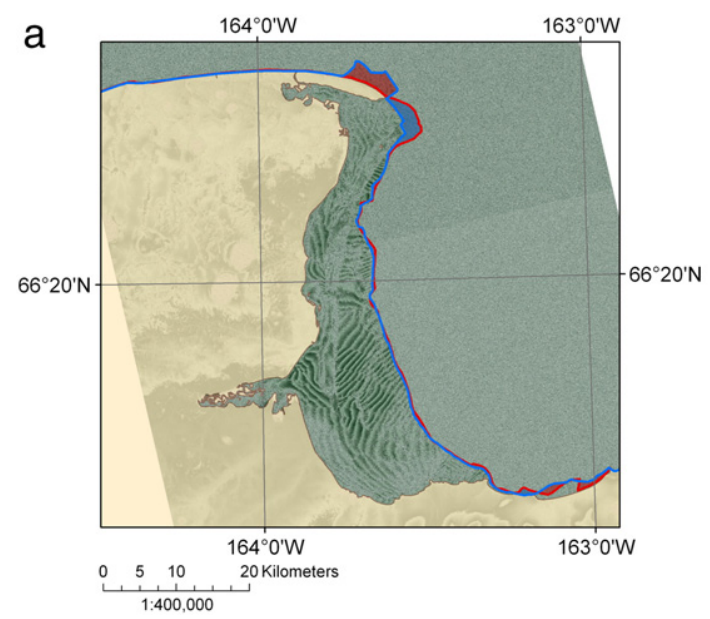

b

\begin{tabular}{lr}
\hline \multicolumn{2}{c}{ Statistical Parameters $\left(\mathrm{km}^{2}\right)$} \\
\hline Mean & 0.21 \\
Standard Deviation & 1.34 \\
Minimum & -2.73 \\
Maximum & 3.83 \\
\hline Sum Positive & 9.40 \\
\hline Sum Negative & -6.40 \\
\hline Number of Segments & 24 \\
\hline
\end{tabular}

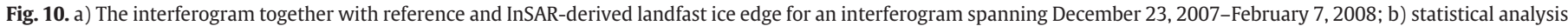

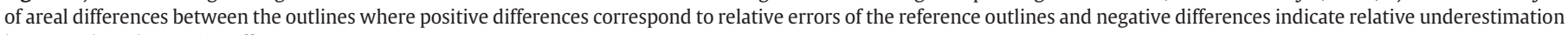
by InSAR-based mapping efforts.

fringe density (marked by black ellipses) associated with significant deformation indicative of potential instability. Fig. 11b shows the twodimensional motion vectors measured from sub-pixel quality crosscorrelation techniques. In coherent areas of interferograms, relative image shifts can be measured with accuracies of the order of $1 / 10$ to $1 / 20$ th of a resolution cell, due to the wide-bandwidth nature of the speckle signature inherent to SAR images. The measurement accuracy is dependent on the patch size used in the analysis, the image resolution, and the interferometric coherence. A detailed description of the achievable accuracies can be found in Bamler and Eineder (2005). The colors in Fig. 11b indicate the magnitude of the motion that occurred in the landfast ice over the time interval covered by the interferogram. Deformation of up to $10 \mathrm{~m}$ was detected in areas of highest fringe density. The black arrows in Fig. 11b show the direction of motion extracted from the two-dimensional shift estimates for those regions that yielded spatially consistent motion vectors. The
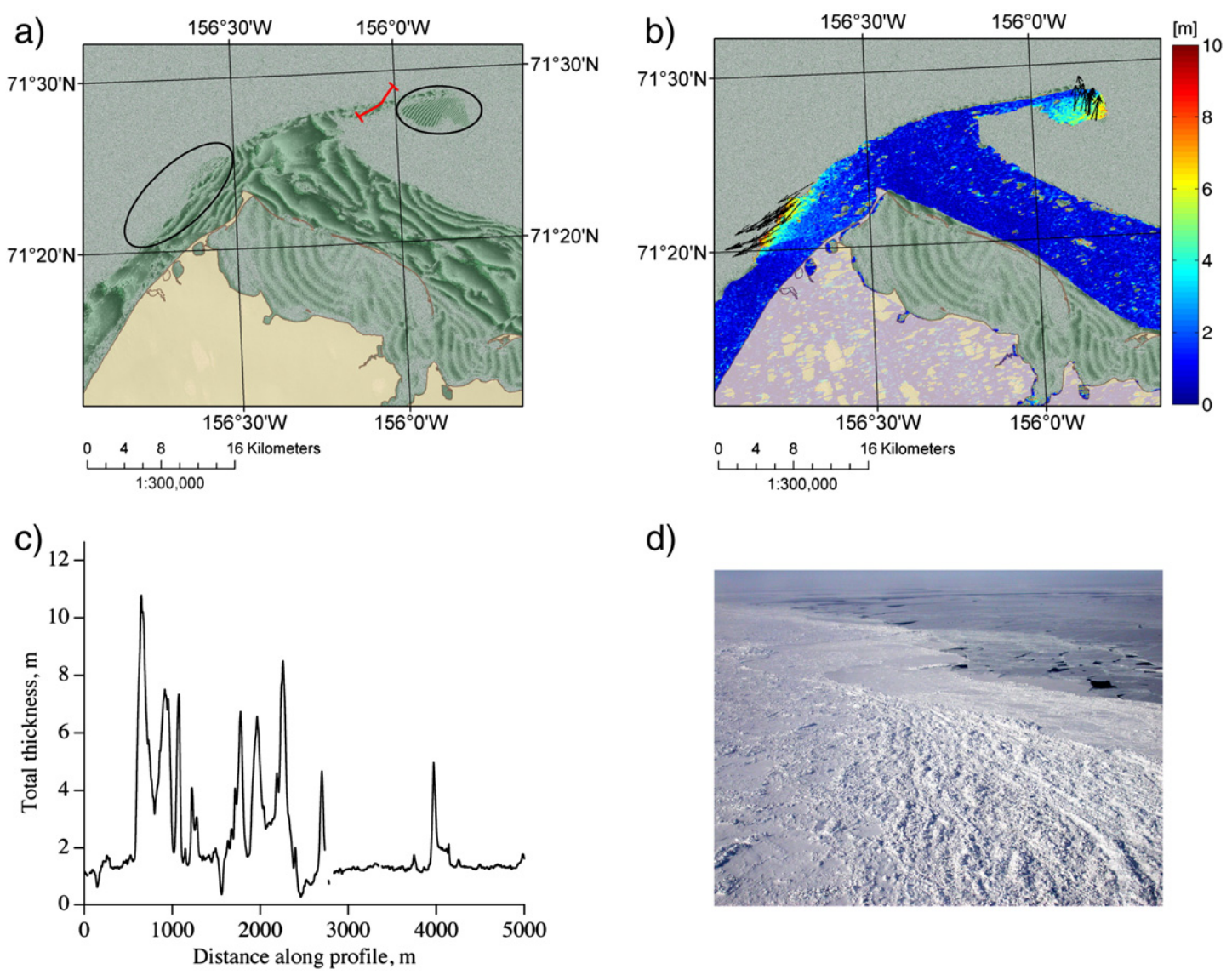

d)

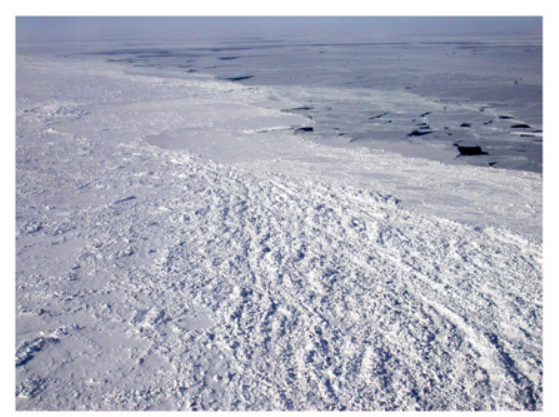

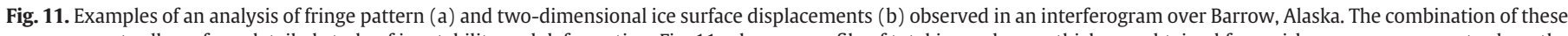

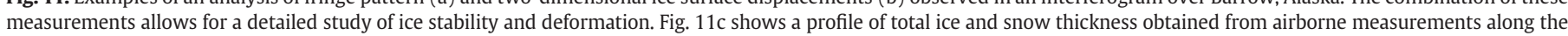
red line shown in (a) on 15 April 2008. Fig. 11d shows the shear ridges corresponding to the thick, deformed ice as seen from the aircraft during the thickness survey. 
motion of the patch to the east is consistent with the landfast ice motion identified and illustrated in Fig. 9b. A strong shear motion has been identified for the area to the west of Point Barrow (both from SAR imagery and the coastal radar at Barrow), which was identified as an area of hinging in Section 4.2.2.

To illustrate the value of such InSAR-derived information in assessing ice displacement and stability, and to further explore the nature of the linear feature of stable ice jutting out from the landfast ice toward the Northeast (Fig. 11b), we have analyzed concurrent ice thickness data. Airborne measurements of ice thickness were obtained by electromagnetic induction techniques, as detailed by Haas et al. (2010, 2009). Shown here (Fig. 11b,c) are part of the thickness surveys covering sea ice that had been identified as grounded shear ridges (Fig. 11d) based on information provided by local ice experts (Brower, Personal Communication, 2008). The thickness data also indicate that ridge thicknesses were sufficient to touch the seafloor and partially ground the ice, thereby stabilizing the landfast ice cover. However, during the deformation process with landfast ice interacting with the offshore ice pack, differential motion of semi-grounded ridges was sufficient to deform thinner ice (in some areas below $1 \mathrm{~m}$ thick, Fig. 11c) south of the line of grounded ridges, explaining the fringe patterns and lack of coherence observed in this part of the interferogram (Figs. 9b and 11a). Hence, interpretation of features such as those shown in Fig. 11a and b can provide important insight into the distribution and degree of grounding of pressure ridges and other landfast ice features important in assessing ice stability. Local ice experts also use the presence of ridge zones over shoals such as those shown in Fig. 11d as an indication of ice stability for long stretches to the Southwest of such features (Brower, Personal Communication, 2008; Leavitt, Personal Communication, 2009).

\subsection{Spatial and temporal coverage of Arctic coasts with L-band InSAR data}

In addition to demonstrating the technological feasibility of InSAR for landfast ice mapping, from an operational perspective it needs to be ascertained that current and future L-band InSAR temporal and spatial coverage is sufficient for key applications. Fig. 12 illustrates the spatial and multi-temporal coverage of ALOS PALSAR images for the Alaskan Arctic coast in winter of 2007/08 as a representative example. In Fig. 12, only available ALOS PALSAR imagery suitable for interferometry is shown, while other acquisitions are ignored. Here, ALOS PALSAR is used as a proxy for all currently available spaceborne L-band SAR data. Frames colored in blue were covered twice between October 2007 and April 2008, yielding one 46-day interferogram. Areas in red were covered three times, producing two independent 46-day interferograms. Green and yellow areas were covered four and five times, respectively, potentially enabling an analysis of the entire landfast ice season. Fig. 12 also shows that, at this geographic latitude, neighboring swaths show almost $40 \%$ overlap. For areas within these overlaps the number of coverages per season increases strongly, as the information from all overlapping swaths can be combined.

While the coverage shown in Fig. 12 is typical for the ALOS PALSAR mission, the specific spatio-temporal sampling does vary from year to year. This is mainly due to the mode of operation of the ALOS mission. ALOS carries three different instruments, two optical sensors and one SAR sensor, which compete for system bandwidth and duty cycle. Additionally, the ALOS mission is divided into sub-cycles of 46-day duration. Within these cycles the satellite is operating in a constant mode, while the operational mode may change between cycles. The design of these modes is defined by weighing a large variety of user interests. The setup of consecutive modes of the PALSAR sensor does therefore not always provide data that are suitable for InSAR applications. In winter of 2008/09, for example, consecutive modes of PALSAR often varied in the used incidence angle and polarimetric mode, which is unsuitable for InSAR applications even if other sensor settings remained unchanged.

Although not all regions of the Arctic are covered with sufficient frequency by currently available L-band SAR missions, the future of Lband SAR for landfast ice detection looks bright. This is mostly due to a series of low-frequency SAR sensors that are scheduled to be launched in the near future. Japan is preparing ALOS-2 which will carry a SAR sensor only and therefore reduce the amount of user and sensor conflicts. NASA is currently preparing for its L-band SAR mission DESDynI and is collaborating with the German Aerospace Center on preparations for TanDEM-L, a DESDynI analog. Besides these L-band missions, ESA will be launching its P-band SAR mission BIOMASS, which might show capabilities similar to ALOS PALSAR for landfast ice monitoring. All these future missions will also provide faster revisit times ( 8 days for DESDynI and TanDEM-L, 14 days for ALOS-2, and between 25 and 45 days for BIOMASS) that will improve interferometric coherence and increase the multi-temporal coverage of each landfast ice season. It is hence likely that using the approach demonstrated here, an accurate, complete mapping of landfast ice distribution throughout the Arctic is possible, which is of value both in the context of the importance of landfast ice for Arctic ecosystems and people (Eicken et al., 2009) and its role in ocean-atmosphere exchange.

\section{Conclusions}

Landfast sea ice along Alaska's coast remains interferometrically coherent in L-band SAR imagery over time intervals of at least 46 days. This makes it possible to distinguish landfast sea ice from drifting ice or open water based on interferometric coherence. We have developed an automated technique that agrees well with existing

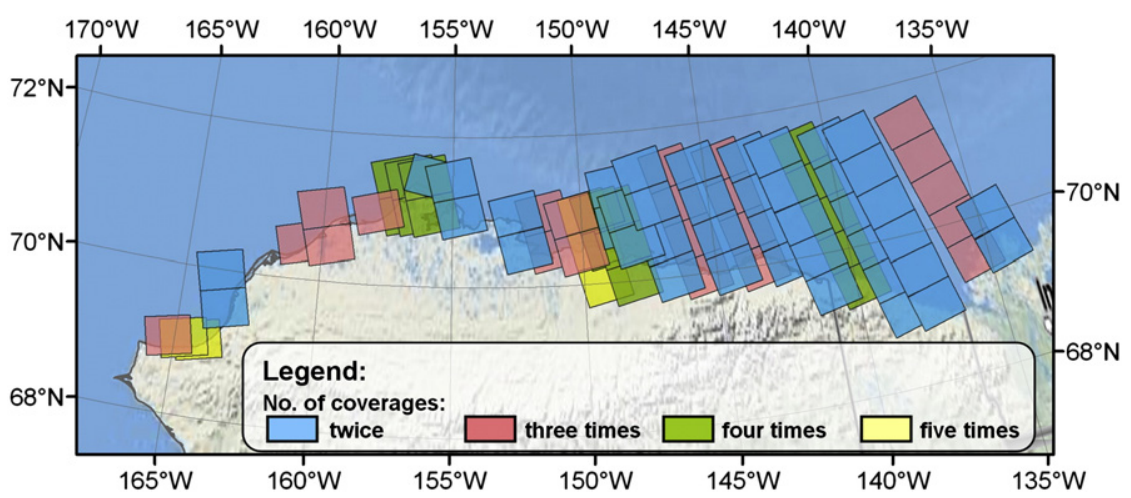

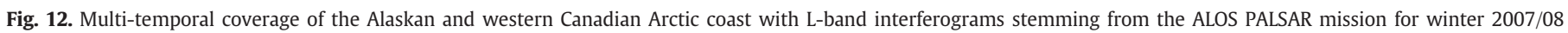
(October 2007 through April 2008). 
SAR-based techniques for delineating landfast ice, though some level of inspection is necessary to correctly interpret unlikely landfast ice configurations. While the presented approach was developed for Arctic environments, in principle L-band InSAR should be applicable anywhere landfast ice is found. However, there may be specific regional or seasonal processes (for example snow ice formation in Antarctica) that may reduce its accuracy in some cases. Therefore, any comprehensive analysis of global landfast ice will require a multi sensor approach to achieve robust mapping results under a wide range of conditions.

Besides landfast ice mapping, L-band SAR interferometry also shows promise for investigating the ambiguous realm of landfast ice motion. By definition, landfast ice is stationary, but clearly there is an amount of lateral motion that can occur without rendering the ice non-landfast. In this study we highlighted one case where we were able to identify discrete zones of sub-pixel motion within the landfast ice. Although small, such motion can be significant for structures within or beneath the landfast ice. Furthermore the boundaries of such zones may be related to the presence of grounded, stabilizing features, which we were able to identify through airborne surveys concurrent with InSAR acquisition. Combined with such groundbased observations, L-band InSAR has the potential to expand our understanding of how landfast ice responds to dynamic forcing and the role that grounded ridges play in stabilizing it.

Although the spatio-temporal coverage of Arctic coasts with L-band InSAR data is currently limited, a larger fleet of upcoming low-frequency SAR systems with improved spatial coverage and temporal revisit cycle will render L-band SAR interferometry a promising tool for continuous observation of global landfast ice areas.

\section{Acknowledgments}

We acknowledge funding support by the Bureau of Ocean Energy Management, Regulation and Enforcement, administered through the Coastal Marine Institute at the University of Alaska Fairbanks. Matching funds were provided by the Conoco-Phillips and Shell corporations. Airborne ice thickness flights and coastal radar observations were made possible through support from the National Science Foundation's Arctic Observing Network Program (OPP0632398). We acknowledge the Japanese Space Exploration Agency JAXA as well as the Alaska Satellite Facility for providing the ALOS PALSAR data sets used in this study. We are grateful to Christian Haas for his support of the thickness flights. Any opinions, findings, and conclusions or recommendations expressed in this publications are those of the authors and do not necessarily reflect the views of the aforementioned institutions.

\section{References}

Adam, S., Pietroniro, A., \& Brugman, M. M. (1997). Glacier snow line mapping using ERS-1 SAR imagery. Remote Sensing of Environment, 61(1), 46-54.

Alt, B. T., Wilson, K., \& Carrieres, T. (2006). A case study of old-ice import and export through Peary and Sverdrup Channels in the Canadian Arctic Archipelago: 19982005. Annals of Glaciology, 44(1), 329-338.

Bamler, R., \& Eineder, M. (2005). Accuracy of differential shift estimation by correlation and split-bandwidth interferometry for wideband and Delta-k SAR systems. IEEE Geoscience and Remote Sensing Letters, 2(2), 151-155.

Bamler, R., \& Hartl, P. (1998). Synthetic aperture radar interferometry. Inverse Problems, 14(4), R1-R54.

Brower, A. S. (2008). Personal communication.

Dammert, P. B. G., Lepparanta, M., \& Askne, J. (1998). SAR interferometry over Baltic Sea ice. International Journal of Remote Sensing, 19(16), 3019-3037.

Divine, D. V., \& Dick, C. (2006). Historical variability of sea ice edge position in the Nordic Seas. Journal of Geophysical Research-Oceans, 111(C1).

Divine, D. V., Korsnes, R., \& Makshtas, A. P. (2004). Temporal and spatial variation of shore-fast ice in the Kara Sea. Continental Shelf Research, 24(15), 1717-1736.

Druckenmiller, M. L., Eicken, H., Johnson, M. A., Pringle, D. J., \& Williams, C. C. (2009). Toward an integrated coastal sea-ice observatory: System components and a case study at Barrow, Alaska. Cold Regions Science and Technology, 56(2-3), 61-72.
Eicken, H., Lovecraft, A. L., \& Druckenmiller, M. L. (2009). Sea-ice system services: A framework to help identify and meet information needs relevant for arctic observing networks. Arctic, 62(2), 119-136.

Erten, E., Reigber, A., Hellwich, O., \& Prats, P. (2009). Glacier velocity monitoring by maximum likelihood texture tracking. IEEE Transactions on Geoscience and Remote Sensing, 47(2), 394-405.

Fraser, A. D., Massom, R. A., \& Michael, K. J. (2010). Generation of high-resolution East Antarctic landfast sea-ice maps from cloud-free MODIS satellite composite imagery. Remote Sensing of Environment, 114(12), 2888-2896.

Gandhi, P. P., \& Kassam, S. A. (1988). Analysis of CFAR processors in homogeneous background. IEEE Transactions on Aerospace and Electronic Systems, 24(4), 427-445.

Gatelli, F., Guamieri, A. M., Parizzi, F., Pasquali, P., Prati, C., \& Rocca, F. (1994). The wavenumber shift in SAR interferometry. IEEE Transactions on Geoscience and Remote Sensing, 32(4), 855-865.

Giles, A. B., Massom, R. A., \& Lytle, V. I. (2008). Fast-ice distribution in East Antarctica during 1997 and 1999 determined using RADARSAT data. Journal of Geophysical Research-Oceans, 113(C2).

Goldstein, R. M., \& Werner, C. L. (1998). Radar interferogram filtering for geophysical applications. Geophysical Research Letters, 25(21), 4035-4038.

Haas, C., Hendricks, S., Eicken, H., \& Herber, A. (2010). Synoptic airborne thickness surveys reveal state of Arctic sea ice cover. Geophysical Research Letters, 37.

Haas, C., Lobach, J., Hendricks, S., Rabenstein, L., \& Pfaffling, A. (2009). Helicopter-borne measurements of sea ice thickness, using a small and lightweight, digital EM system. Journal of Applied Geophysics, 67(3), 234-241.

Haralick, R. M., \& Shapiro, L. G. (1992). Computer and robot vision. : Addison-Wesley Longman Publishing Co., Inc. 630 pp.

Hoen, E. W., \& Zebker, H. A. (2000). Penetration depths inferred from interferometric volume decorrelation observed over the Greenland ice sheet. IEEE Transactions on Geoscience and Remote Sensing, 38(6), 2571-2583.

Lang, O., 2003. Radar Remote Sensing in Western Antarctica with Special Emphasis on Differential Interferometry. Dissertation Thesis, Julius-Maximilians-Universitaet Wuerzburg, Wuerzburg, $127 \mathrm{pp}$.

Lantuit, H., \& Pollard, W. H. (2008). Fifty years of coastal erosion and retrogressive thaw slump activity on Herschel Island, southern Beaufort Sea, Yukon Territory, Canada. Geomorphology, 95(1-2), 84-102.

Leavitt, J. (2009). Personal communication.

Lee, J. S. (1981). Speckle analysis and smoothing of synthetic aperture radar images. Computer Graphics and Image Processing, 17(1), 24-32.

Lee, J. S., Schuler, D. L., Lang, R. H., \& Ranson, K. J. (1994). K-distribution for multi-look processed polarimetric SAR imagery, Geoscience and Remote Sensing Symposium, 1994. IGARSS '94. Surface and Atmospheric Remote Sensing: Technologies, Data Analysis and Interpretation., International, vol. 4. (pp. 2179-2181).

Lu, Z., Wicks, C., Kwoun, O., Power, J. A., \& Dzurisin, D. (2005). Surface deformation associated with the March 1996 earthquake swarm at Akutan Island, Alaska, revealed by C-band ERS and L-band JERS radar interferometry. Canadian Journal of Remote Sensing, 31(1), 7-20.

Mahoney, A., Eicken, H., Gaylord, A. G., \& Shapiro, L. (2007). Alaska landfast sea ice: Links with bathymetry and atmospheric circulation. Journal of Geophysical Research-Oceans, 112(C2).

Mahoney, A., Eicken, H., Graves, A., Shapiro, L., \& Cotter, P. (2004). Landfast sea ice extent and variability in the Alaskan Arctic derived from SAR imagery, Geoscience and Remote Sensing Symposium, 2004. IGARSS '04. Proceedings. 2004 IEEE International, vol. 3. (pp. 2146-2149).

Mahoney, A., Eicken, H., Shapiro, L., \& Graves, A. (2006). Defining and locating the seaward landfast ice edge in northern Alaska. In J. P. Dempsey (Ed.), 18th International Conference on Port and Ocean Engineering under Arctic Conditions (POAC '05), Potsdam, N.Y. (pp. 991-1001).

Meyer, F. J. (2007). Topography and displacement of polar glaciers from multi-temporal SAR interferograms. Polar Record, 43(227), 331-343.

Meyer, F., Hinz, S., Laika, A., Weihing, D., \& Bamler, R. (2006). Performance analysis of the TerraSAR-X traffic monitoring concept. ISPRS Journal of Photogrammetry and Remote Sensing, 61(3-4), 225-242.

Morris, K., Li, S. S., \& Jeffries, M. (1999). Meso- and microscale sea-ice motion in the East Siberian Sea as determined from ERS-1 SAR data. Journal of Glaciology, 45(150), 370-383.

Partington, K. C. (1998). Discrimination of glacier facies using multi-temporal SAR data. Journal of Glaciology, 44(146), 42-53.

Rignot, E. (2001). Evidence for rapid retreat and mass loss of Thwaites Glacier, West Antarctica. Journal of Glaciology, 47(157), 213-222.

Rignot, E., \& Kanagaratnam, P. (2006). Changes in the velocity structure of the Greenland ice sheet. Science, 311(5763), 986-990.

Rignot, E., Bamber, J. L., Van den Broeke, M. R., Davis, C., Li, Y., Van de Berg, et al. (2008). Recent Antarctic ice mass loss from radar interferometry and regional climate modelling. Nature Geoscience, 1(2), 106-110.

Rosen, P., Hensley, S., Peltzer, G., \& Simons, M. (2004). Updated repeat orbit interferometry package released. EOS, Transactions American Geophysical Union, 85(5), 47.

Rosen, P. A., Hensley, S., Zebker, H. A., Webb, F. H., \& Fielding, E. J. (1996). Surface deformation and coherence measurements of Kilauea volcano, Hawaii, from SIR-C radar interferometry. Journal of Geophysical Research-Planets, 101(E10), 23109-23125.

Rosenqvist, A., Shimada, M., Ito, N., \& Watanabe, M. (2007). ALOS PALSAR: a pathfinder mission for global-scale monitoring of the environment. IEEE Transactions on Geoscience and Remote Sensing, 45(11), 3307-3316.

Sandwell, D. T., Myer, D., Mellors, R., Shimada, M., Brooks, B., \& Foster, J. (2008) Accuracy and resolution of ALOS interferometry: vector deformation maps of the Father's Day intrusion at Kilauea. Geoscience and Remote Sensing, IEEE Transactions on, 46(11), 3524-3534. 
Seymour, M. S., \& Cumming, I. G. (1994). Maximum likelihood estimation for SAR interferometry, Geoscience and Remote Sensing Symposium, 1994. IGARSS '94. Surface and Atmospheric Remote Sensing: Technologies, Data Analysis and Interpretation., International, vol. 4. (pp. 2272-2275).
World Meteorological Organization (1970). WMO sea-ice nomenclature, terminology, codes and illustrated glossary, WMO/DMM/BMO 259-TP-145. Geneva: Secretariat of the WMO. Zebker, H. A., \& Villasenor, J. (1992). Decorrelation in interferometric radar echoes. IEEE Transactions on Geoscience and Remote Sensing, 30(5), 950-959. 